\title{
Comparison of Ambient Radon Concentrations in Air in the Northern Mojave Desert from Continuous and Integrating Instruments
}

\author{
prepared by \\ David S. Shafer, David McGraw, Lynn H. Karr, Greg McCurdy, \\ Tammy L. Kluesner, and Karen J. Gray \\ and \\ Jeffrey J. Tappen \\ Navarro Nevada Environmental Services
}

submitted to:

U.S. Department of Energy,

National Nuclear Security Administration,

Nevada Site Office

March 2010

Publication No. 45232 
Reference herein to any specific commercial product, process, or service by trade name, trademark, manufacturer, or otherwise, does not necessarily constitute or imply its endorsement, recommendation, or favoring by the United States Government or any agency thereof or its contractors or subcontractors.

Available for sale to the public from:

U.S. Department of Commerce

National Technical Information Service

5301 Shawnee Road

Alexandria, VA 22312

Phone: 800.553.6847

Fax: 703.605.6900

Email: orders@ntis.gov

Online ordering: http://www.osti.gov/ordering.htm

Available electronically at http://www.osti.gov/bridge

Available for a processing fee to the U.S. Department of Energy and its contractors, in paper, from:

U.S. Department of Energy

Office of Scientific and Technical Information

P.O. Box 62

Oak Ridge, TN 37831-0062

Phone: 865.576.8401

Fax: 865.576.5728

Email: reports@adonis.osti.gov 


\title{
Comparison of Ambient Radon Concentrations in Air in the Northern Mojave Desert from Continuous and Integrating Instruments
}

\author{
prepared by \\ David S. Shafer, David McGraw, Lynn H. Karr, Greg McCurdy, \\ Tammy L. Kluesner, and Karen J. Gray \\ Division of Hydrologic Sciences, \\ Desert Research Institute \\ Nevada System of Higher Education \\ and \\ Jeffrey J. Tappen \\ Navarro Nevada Environmental Services
}

Publication No. 45232

submitted to

U.S. Department of Energy, National Nuclear Security Administration,

Nevada Site Office

March 2010

The work upon which this report is based was supported by the U.S. Department of Energy under Contract \# DE-AC52-06NA26383. Approved for public release; further dissemination unlimited. 
THIS PAGE LEFT INTENTIONALLY BLANK 


\begin{abstract}
As part of a program to characterize and baseline environmental parameters, ambient radon-222 (Rn) monitoring was conducted in the rural community of Amargosa Valley, NV, the closest community to Yucca Mountain. Passive integrating and continuous Rn monitoring instruments were deployed adjacent to the Community Environmental Monitoring Program (CEMP) station in Amargosa Valley. The CEMP station provided real-time ambient gamma exposure and meteorological data used to correct the integrated $\mathrm{Rn}$ measurements, verified the meteorological data collected by the continuous $\mathrm{Rn}$ monitoring instrument, and for provided instrumentation for evaluating the relationships between meteorological conditions and Rn concentrations. Hourly Rn concentrations in air measured by the continuous Rn monitoring instrument (AlphaGUARD ${ }^{\circledR}$ ) were compared to the average hourly values for the integrating Rn measurements (E-PERM $®$ ) by dividing the total Rn measurements by the number of hours the instruments were deployed. The results of the comparison indicated that average hourly ambient Rn concentrations as measured by both methods ranged from 0.2 to 0.4 pico-curies per liter of air. Ambient Rn values for the AlphaGUARD exhibited diurnal variations. When Rn concentrations were compared with measurements of temperature $(\mathrm{T})$, barometric pressure, and relative humidity, the correlation (inversely) was highest with T, albeit weakly.
\end{abstract}


THIS PAGE LEFT INTENTIONALLY BLANK 


\section{CONTENTS}

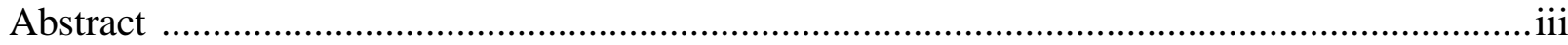

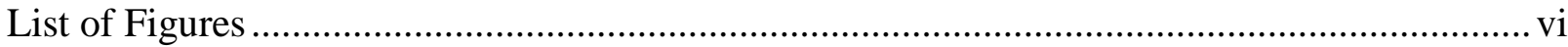

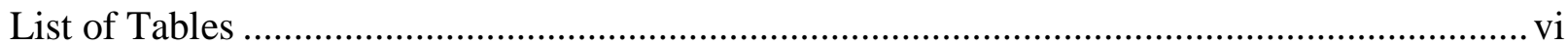

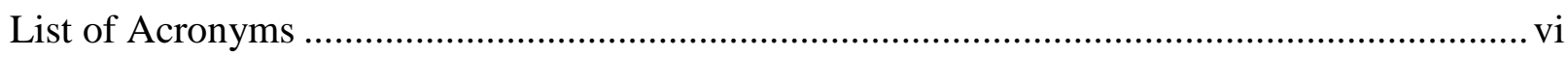

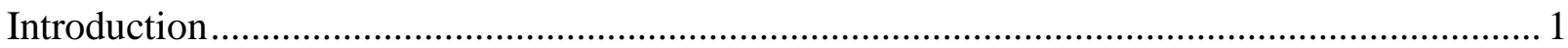

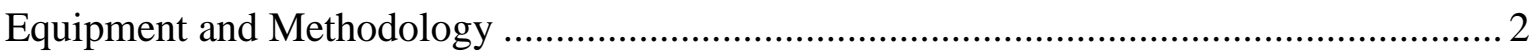

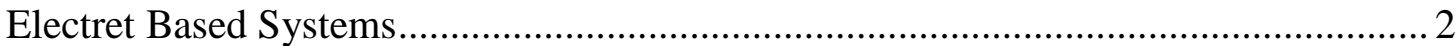

Track-Etch Based Systems ........................................................................................ 3

Pulse Ionization Based Systems. ................................................................................ 3

Laboratory Comparison of Integrating Radon Monitors ................................................... 4

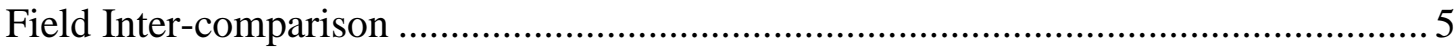

Radtrak ${ }^{\circledR}$ Performance ......................................................................................... 5

E-PERM ${ }^{\circledR}$ Performance Evaluation.................................................................... 5

Continuous Rn Monitoring System ……………………........................................... 7

AlphaGUARD System Environmental Sensors Performance......................................... 7

Ambient Rn-222 Measurements, Amargosa Valley, Nevada............................................. 10

Continuous Rn Monitoring (AGS) ...................................................................... 10

Real-time Rn Data Transmission........................................................................... 10

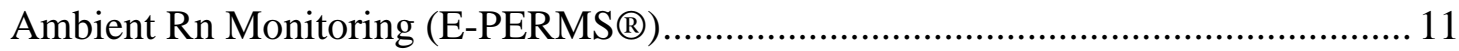

Comparison of Ambient Rn-222 Measurements .......................................................... 12

Comparison of AGS Environmental Parameter Measurements with Ambient

Rn-222 Concentration Measurements. ................................................................ 14

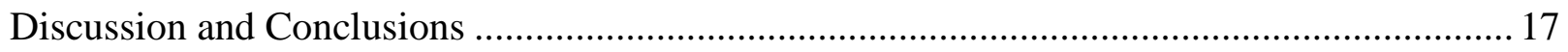

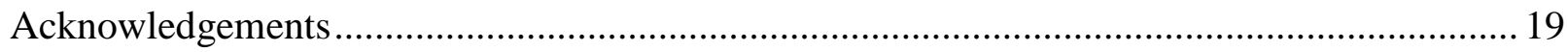

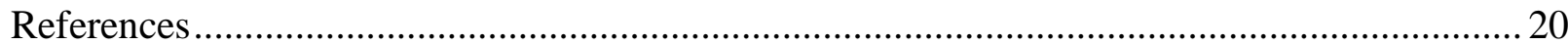

Appendix A: Comparison of Average Radon Concentrations and Meteorological

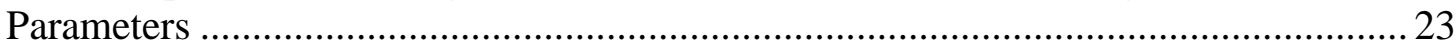

Appendix B: Comparison of AlphaGuard ${ }^{\circledR}$ and CEMP Environmental Data ............................ 29 


\section{LIST OF FIGURES}

1. Location of Amargosa Valley relative to Yucca Mountain............................................. 1

2. E-PERM® electret system (S-chamber, ST-electret, and storage cap). ............................ 2

3. AGS deployed in environmental enclosure in Amargosa Valley..................................... 3

4. Distribution of ambient Rn concentrations. ............................................................. 11

5. Average ambient Rn concentration - short-term from the EPERMS............................. 13

6. Ambient Rn concentrations - long-term from the EPERMS ....................................... 13

7. Principal component analysis of pressure, temperature, and humidity........................... 16

8. Relationship between $\log (\mathrm{Rn})$ and temperature.................................................... 16

\section{LIST OF TABLES}

1. Integrating Rn monitor inter-comparison (US EPA Rn Chamber)................................... 4

2. Average voltage decrease as a function of configuration (Amargosa Valley, NV)............. 6

3. Average voltage decrease as a function of configuration (Las Vegas, NV)...................... 6

4. Effect of the use of activated charcoal on average voltage decrease (Amargosa

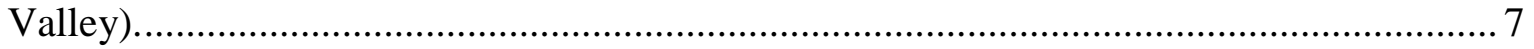

5. Mean temperature comparison, CEMP and AGS ..................................................... 8

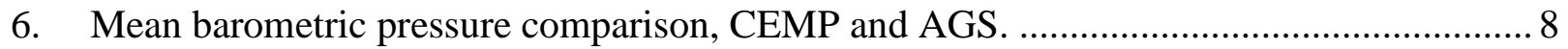

7. Mean relative humidity comparison, CEMP and AGS .............................................. 8

8. Average Rn concentration by monitoring period...................................................... 12

9. Average Rn-222 concentration comparison. (pCi/l) .................................................. 14

10. Correlation coefficients for average monthly ambient Rn-222 concentration and AGSmeasured average monthly temperature, pressure and relative humidity........................ 15

11. Correlation coefficients for average daily ambient Rn-222 concentration and AGSmeasured average daily temperature, pressure and relative humidity. ............................ 15

12. Multiple linear regression results...................................................................... 17

$\begin{array}{ll}\text { AGS } & \text { AlphaGUARD System } \\ \text { CEMP } & \text { Community Environmental Monitoring Program } \\ \text { DOE } & \text { Department of Energy } \\ \text { DRI } & \text { Desert Research Institute } \\ \text { EPA } & \text { Environmental Protection Agency } \\ \text { E-PERM }{ }^{\circledR} & \text { Electret Passive Environmental Radon Monitor } \\ \text { ICU } & \text { Initial Calibration Uncertainty } \\ \text { MEI } & \text { maximally exposed individual } \\ \text { rH } & \text { relative humidity } \\ \text { Rn } & \text { radon }\end{array}$




\section{INTRODUCTION}

In assessing the potential environmental impacts should Yucca Mountain, Nevada (NV) be licensed as a repository for high-level nuclear waste and spent fuel, the Department of Energy (DOE) identified radon-222 (Rn), and its decay progeny, as the main radiological effluents from the facility (DOE, 2002; DOE, 2007). DOE estimated that exposure to these radioactive effluents could account for greater than 99 percent of potential health impacts to the reasonably maximally exposed individual (RMEI) (DOE, 2002; DOE, 2007). The RMEI is a theoretical receptor located approximately 18 kilometer (11 miles) south of Yucca Mountain, in the general direction of Amargosa Valley (DOE, 2007).

During the early 1990's, the Nevada Bureau of Mines and Geology and the Nevada Division of Health, in conjunction with the U.S. Environmental Protection Agency (EPA), conducted Rn monitoring throughout Nevada (Rigby et al., 1994). The program included measurement of both indoor and outdoor concentrations using passive integrating Rn monitoring systems. Concurrent with this program, DOE, conducted a program to characterize the radiological environment in the vicinity of Yucca Mountain (DOE, 1988). This program included activities to characterize the ambient Rn-222 concentrations at several locations within the project site boundaries, using both passive integrating and continuous Rn monitoring technologies (Griffin, 1994; Liu, et al., 1995).

However, neither program monitored the ambient Rn concentration in Amargosa Valley, the nearest town to Yucca Mountain (Fig. 1). In 2006, the Desert Research Institute (DRI of the

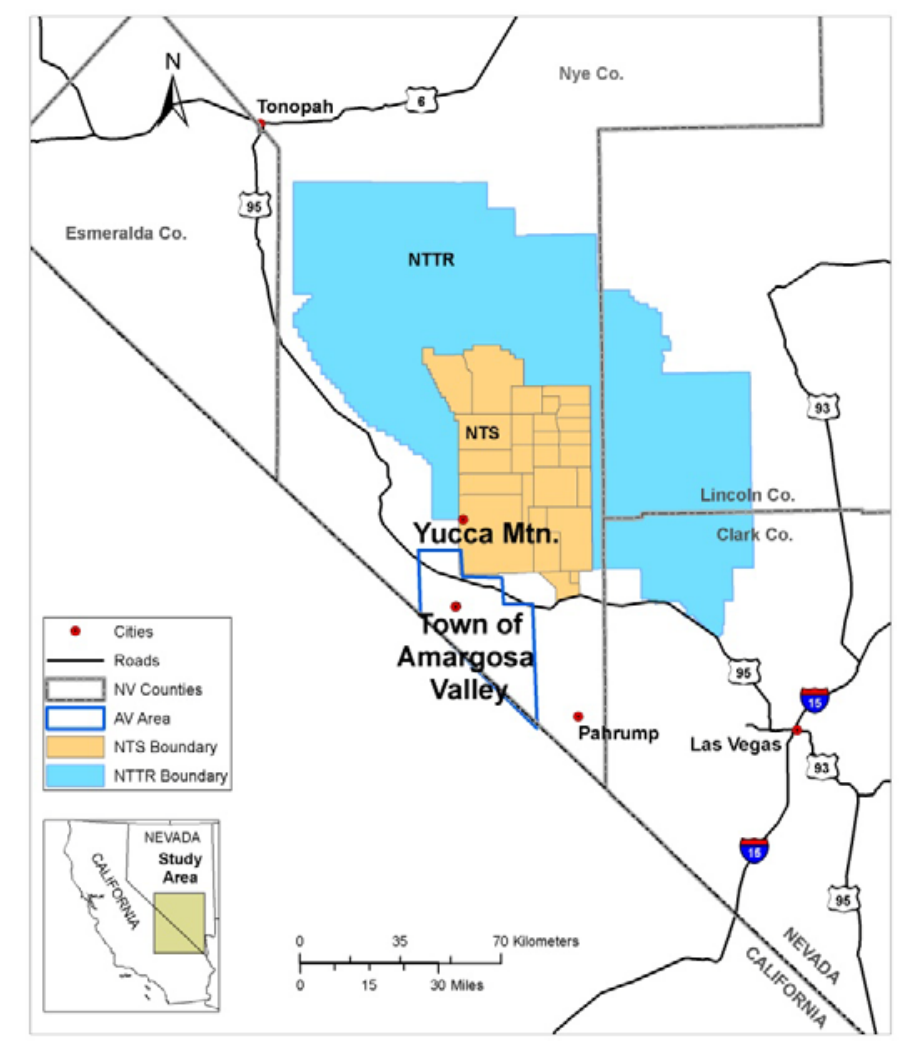

Figure 1. Location of Amargosa Valley relative to Yucca Mountain. 
Nevada System of Higher Education) initiated an evaluation of the functional and operational characteristics of three passive Rn monitoring systems. As a result of this evaluation, DRI initiated an ambient Rn monitoring program in April 2007, to collect ambient Rn data by deploying these systems adjacent to the Community Environmental Monitoring Program (CEMP) station in Amargosa Valley. A description of the CEMP and the monitoring capabilities at each station is available at http://www.cemp.dri.edu/.

\section{Equipment and Methodology}

The DRI selected three passive Rn monitoring systems, two integrating and one continuous, for evaluation prior to initiating Rn monitoring in Amargosa Valley. The integrating systems selected were the Electret Passive Environmental Rn Monitor (E-PERM ®) system by Rad Elec, Inc., and the Radtrak ${ }^{\circledR}$ system by Landauer, Inc. The continuous monitoring system selected was the AlphaGUARD ${ }^{\circledR}$ system by SAPHYMO GmbH (once known as Genitron, Inc.). All of the systems required protection from environmental conditions and were deployed in an environmental enclosure at the monitoring site.

\section{Electret Based Systems}

The Electret Passive Environmental Radon Monitor (E-PERM®) system is a passive system that has two components, a monitor and a reader. The monitor consists of a conductive plastic air ionization chamber and an electrically charged Teflon ${ }^{\circledR}$ disk. Figure 2 shows the components of the system. Air, containing Rn, diffuses in to the chamber through a small filtered opening. As the Rn and its progeny decay, the air in the chamber ionizes and negative ions are attracted to the charged Teflon ${ }^{\circledR}$ disk resulting in a decrease in the charge on the disk. The amount of discharge is proportional to the ion concentration and the exposure time. Positively charged ions are attracted to the plastic walls of the chamber and are neutralized. The voltage on the Teflon ${ }^{\circledR}$ disk is read prior to and after deployment. The difference, the voltage discharge, is measured and the corresponding Rn concentration is calculated through an algorithm provided by the manufacturer.

The E-PERMS ${ }^{\circledR}$ require protection from dust and weather conditions. They were placed in a Tyvex ${ }^{\mathrm{TM}}$ bag for dust protection, and then placed in a well ventilated protective structure. The estimated minimum measurable concentration for a multi-week deployment is 0.1 pico-Curies per liter (pCi/l) in air.

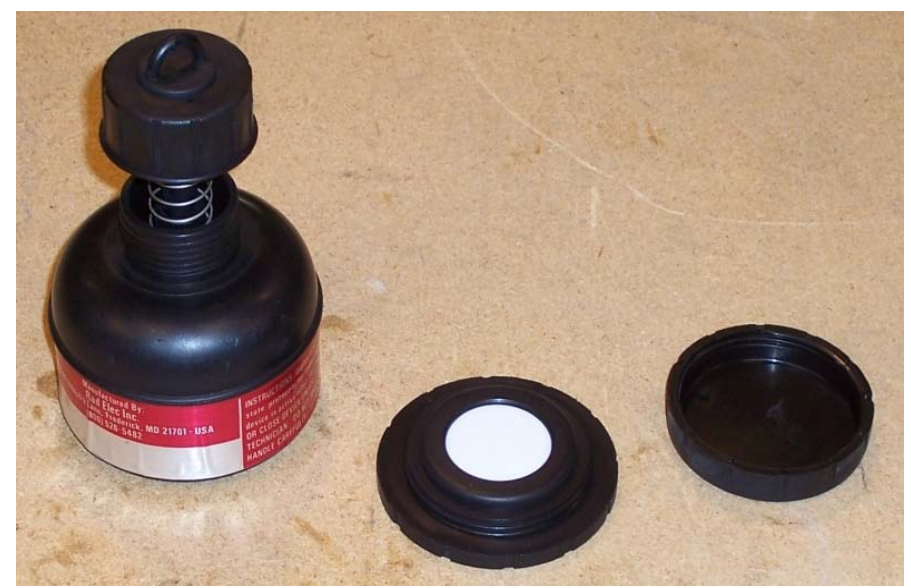

Figure 2. $\quad$ E-PERM® ${ }^{\circledR}$ electret system (S-chamber, ST-electret, and storage cap). 


\section{Track-Etch Based Systems}

The Radtrak ${ }^{\circledR}$ passive integrating system uses a radiosensitive material, ally diglycol carbonate (referred to as CR- $39^{\mathrm{TM}}$ ), as the medium for alpha particle detection. The CR-39 ${ }^{\mathrm{TM}}$ is contained in plastic casing that has filtered openings at one end, which allow only Rn to diffuse into the casing. Other particulate radionuclides, including Rn decay progeny, are filtered out. As the $\mathrm{Rn}$ in the casing decays, the emitted alpha particles penetrate the CR- $39^{\mathrm{TM}}$ leaving a track as the alpha particle travels into the material. The Radtrak® detector is returned to the manufacturer for processing at the end of the monitoring period. The CR- $39^{\mathrm{TM}}$ is processed and the density of the "tracks" within the CR- $39^{\mathrm{TM}}$ is optically determined. A Rn concentration coefficient is utilized to convert total track density into a Rn concentration in $\mathrm{pCi} / \mathrm{l}$. When measuring ambient Rn concentrations, these detectors require protection from meteorological conditions and are placed in an environmental enclosure. The Radtrak ${ }^{\circledR}$ system has a reported minimum level of detection for $\mathrm{Rn}$ of $30 \mathrm{pCi} / \mathrm{l}$-days, based on an exposure period 90 days at a concentration of $0.3 \mathrm{pCi} / \mathrm{l}$ (http//www:Idrsolutions.landauerinc.com; accessed 02-07-08).

\section{Pulse Ionization Based Systems.}

The continuous Rn monitoring system selected for evaluation, the AlphaGUARD System (AGS), utilizes pulse-ionization as the measuring technique. The system requires external electrical power. Figure 3 shows the AGS deployed in an environmental enclosure in Amargosa Valley, NV. Rn diffuses through a fiberglass filter into a 0.56-liter counting chamber. The filter diffusion characteristics are designed to allow for the decay of Rn-220, (half-life of $\sim 56$ seconds), a progeny of the naturally occurring radioisotope thorium-232. As the Rn, and progeny decay within the chamber, the air is ionized and the ions are attracted to either the cathode or anode producing an electrical pulse. This pulse is subsequently post-processing via a series of algorithms. The chamber and associated components are located within an aluminum instrument body. Rn measurements are made at a set frequency and average concentrations are

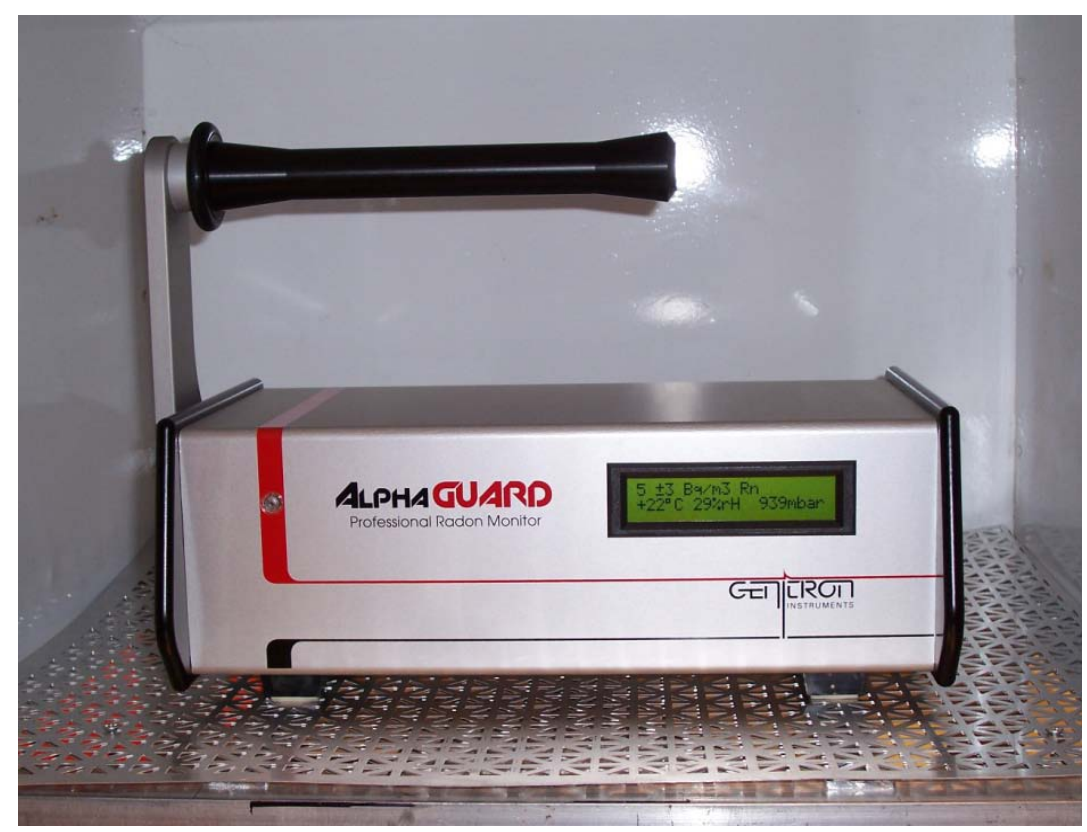

Figure 3. AGS deployed in environmental enclosure in Amargosa Valley. 
recorded on either a 10 minute or 60 minute frequency. The system has a reported lower limit of detection of 0.05 pCi/l (approximately 2 Bequer4els per cubic meter [Bq/m3]) (Genitron, 1998).

Contained within instrument body are a series of environmental sensors that are design to monitor air temperature, barometric pressure, and relative humidity in the immediate vicinity of the instrument. Because the system measures and records data on a set frequency, data must be downloaded periodically to prevent data losses through data overwrite due to limited storage capacity. In addition, the AGS contains an internal quality assurance subsystem that provides information on the operational status of the hardware, e.g. detector signal quality, low voltage, increase in system background, and the quality of the data.

\section{Laboratory Comparison of Integrating Radon Monitors}

To determine the relative response characteristics of the two integrating monitoring systems, the US Environmental Protection Agency, Office of Research and Development, National Exposure Research Laboratory, Las Vegas, NV agreed to let DRI deploy six of each type of monitor, three of each type in a Tyvex ${ }^{\mathrm{TM}}$ bags and three in the open, in an Rn chamber. Due to demands on the use of the chamber, exposure time was limited to 10 days. However, the exposure was at a concentration significantly higher than that expected to occur in the ambient environment, (6.9 pCi/l). Table 1 presents the results of this inter-comparison.

The results of the inter-comparison suggest that placing either type of monitor within a Tyvex $^{\mathrm{TM}}$ bag had no effect on the calculated mean Rn concentration; however, the measurements suggest, as shown by the coefficient of variability, that placing the Radtrak ${ }^{\circledR}$ monitors in Tyvex $^{\text {TM }}$ bags may have altered the systems precision. Measurements by both detector types were within 10-12 percent of the average Rn concentration of $6.9 \mathrm{pCi} / \mathrm{l}$ in the Rn chamber (Budd, 2006). The Rn concentrations measured by the Radtrak ${ }^{\circledR}$ detectors varied significantly, while the E-PERMS ${ }^{\circledR}$ measurements had a much lower degree of variability.

A review of the Radtrak ${ }^{\circledR}$ manufacturer's technical literature indicated that the 10 day exposure at $6.9 \mathrm{pCi} / \mathrm{l}$ did not meet the Radtrak ${ }^{\circledR}$ lower limit of detection of $90 \mathrm{pCi} / \mathrm{l}$-days, based on an exposure of $0.3 \mathrm{pCi} / \mathrm{l}$ for a period of 90 days (Landauer, 2006). As an $\mathrm{x}$ result, it was decided to deploy both systems in Amargosa Valley to evaluate their performance under field conditions.

Table 1. Integrating Rn monitor inter-comparison (US EPA Rn Chamber).

\begin{tabular}{|c|c|c|c|c|}
\hline Detector \# & $\begin{array}{c}\text { Radtrak® }^{\circledR} \text { - } \\
\text { Tyvex }^{\mathrm{TM}} \\
\text { [pCi/l] }^{-}\end{array}$ & $\begin{array}{l}\text { Radtrak }{ }^{\circledR} \text {-Open } \\
\text { Air [pCi/l] }\end{array}$ & $\begin{array}{c}\text { E-PERM®- } \\
\text { Tyvex } \\
\text { [pCi/l] }^{\mathrm{TM}}\end{array}$ & $\begin{array}{c}\text { E-PERM® Open Air } \\
{[\mathrm{pCi} / 1]}\end{array}$ \\
\hline 1 & 7.1 & 7.2 & 6.5 & 6.1 \\
\hline 2 & 10.0 & 8.8 & 6.1 & 6.2 \\
\hline 3 & 6.0 & 6.7 & 6.1 & 6.3 \\
\hline Mean & 7.7 & 7.6 & 6.2 & 6.2 \\
\hline Std Dev & 2.1 & 1.1 & 0.2 & 0.1 \\
\hline Coeff. of Var. & $26.8 \%$ & $14.5 \%$ & $3.7 \%$ & $1.6 \%$ \\
\hline \% Deviation & $11.6 \%$ & $10.1 \%$ & $10.1 \%$ & $10.1 \%$ \\
\hline
\end{tabular}




\section{Field Inter-comparison}

The two passive integrating systems were deployed in Amargosa Valley between April and July 2006; three E-PERMS ${ }^{\circledR}$ and three Radtraks ${ }^{\circledR}$ were placed in separate Tyvex ${ }^{\mathrm{TM}}$ bags and deployed in a modified, well ventilated environmental enclosure one meter above the ground. A second set of Radtraks ${ }^{\circledR}$ was deployed in individual environmental enclosures purchased from the system manufacturer.

\section{$\underline{\text { Radtrak® Performance }}$}

At the end of July 2006, the Radtraks ${ }^{\circledR}$ were retrieved and sent to the manufacturer for analysis. Analysis revealed that four of the six Radtraks ${ }^{\circledR}$, the three placed in the environmental enclosures and one placed in the environmental enclosure, had alpha tracks that were "oversized and looked like bubbles" (Landauer, 2006). The manufacturer acknowledged the cause of these abnormal tracks was unknown. Analysis of the two remaining Radtraks ${ }^{\circledR}$ indicated that the ambient Rn concentration was between $0.4-0.5 \mathrm{pCi} / \mathrm{l}$. Analysis of the E-PERM ${ }^{\circledR}$ measurements for the same period indicated an average ambient Rn concentration of $0.3+/-0.1 \mathrm{pCi} / \mathrm{l}$. Due to the response uncertainties associated with the Radtrak ${ }^{\circledR}$ monitors, it was decided to continue deployment for evaluation purposes only.

The Radtrak ${ }^{\circledR}$ monitors were redeployed at Amargosa Valley in March, 2008 with two placed in a "dog-house" environmental enclosure and two enclosures provided by the manufacturer. These detectors were recovered on July 14, 2008, at which time four additional Radtraks ${ }^{\circledR}$ were deployed in a similar configuration. The Rn monitoring report received from the manufacturer indicated that the Radtraks ${ }^{\circledR}$ deployed in the environmental enclosures were "returned damaged" while those in the dog house showed Rn concentrations of 0.3 and $<0.3 \mathrm{pCi} / \mathrm{l}$. These concentrations are consistent with the average concentration measured by the E-PERMS ${ }^{\circledR}$ for the same period.

Subsequent conversations with manufacturer representatives revealed that the 'damage' to these detectors was "large oversized tracks indicating 'potential heat damage'." A review of the meteorological data from the adjacent CEMP station indicated that the maximum ambient temperature measured for the deployment period was $113^{\circ} \mathrm{F}\left(43^{\circ} \mathrm{C}\right)$, well below the manufacturer's recommended temperature limit of $160^{\circ} \mathrm{F}\left(71.1^{\circ} \mathrm{C}\right)$.

The next set Radtrak ${ }^{\circledR}$ detectors were recovered in January 2009 and sent to the manufacturer for analysis. Consistent with previous results, the manufacturer's monitoring report indicated that those detectors deployed in the environmental enclosures and one of those located in the dog-house were "received damaged", while the other Radtrak indicated a Rn concentration of $<0.3 \mathrm{pCi} / \mathrm{l}$. A review of the temperature data collected at the adjacent CEMP station indicated that the average ambient temperature for the deployment period was approximately $65^{\circ} \mathrm{F}\left(18.3^{\circ} \mathrm{C}\right)$, with a maximum temperature of $112^{0} \mathrm{~F}\left(44.4^{\circ} \mathrm{C}\right)$. The apparent sensitivity to ambient temperature negatively affected the functionality and usefulness of these detectors.

\section{$\underline{\text { E-PERM }{ }^{\circledR} \text { Performance Evaluation }}$}

The E-PERM ${ }^{\circledR}$ system functions essentially as an air ionization chamber; therefore, any Rn measurement must be corrected for effect of background gamma exposure on the air in the chamber. The system manufacturer recommends essentially two methods for correcting E-PERM ${ }^{\circledR}$ measurements. The first utilizes an Rn concentration equivalent gamma exposure rate factor in conjunction with either a state-specific or site-specific measured exposure rates. The 
second involves measuring the effect of ambient gamma on the E-PERM ${ }^{\circledR}$ directly using additional E-PERM ${ }^{\circledR}$ S sealed in a Mylar ${ }^{\circledR}$ bag. The relative effectiveness of these two methods was also part of the performance evaluation of the system. Because there is a Pressurized Ionization Chamber $^{\mathrm{TM}}$ (PIC) at the CEMP site which provides ambient gamma exposure rate at Amargosa Valley, site-specific exposure rates measurements in conjunction with Rn concentration equivalent gamma exposure rate factor were used to correct for gamma exposure.

The Rn concentration equivalent gamma exposure rate factor varies as a function of the size of the E-PERM® ${ }^{\circledR}$ chamber deployed. Measurements in Amargosa Valley utilized 210 milliliter "S"-chambers that had a Rn concentration equivalent gamma exposure rate factor of 0.087 picoCuries per liter (pCi/l) per microRoentgen per hour (uR/hr) (Rad Elec Inc., 2002). This factor was multiplied by the ambient gamma exposure rate for the measurement site, and the resulting value was subtracted from the calculated Rn concentration.

The second method for measuring the effect of ambient gamma on the E-PERM® involved the use of additional E-PERM ${ }^{\circledR}$ sealed in Mylar bags (Rad Elec Inc., 2002). In this method, E-PERM ${ }^{\circledR}$ s sealed in Mylar bags were deployed with E-PERM ${ }^{\circledR S}$ in Tyvex ${ }^{\mathrm{TM}}$ bags. At the end of the measurement period, the average voltage decrease for the E-PERMs ${ }^{\circledR}$ in the Tyvex $^{\mathrm{TM}}$ bags (Rn plus gamma) was corrected for gamma exposure by adding the average voltage decrease measured by the E-PERM ${ }^{\circledR}$ in the Mylar bags (gamma only). To evaluate this method of gamma exposure correction, three E-PERM ${ }^{\circ} \mathrm{S}$ in Mylar bags were deployed with three E-PERM ${ }^{R S}$ in Tyvex ${ }^{\mathrm{TM}}$ bags for approximately monthly periods between April through August 2006 at the CEMP stations in Amargosa Valley and at the DRI campus in Las Vegas. Tables 2 and 3 present comparisons of the average voltage decrease for each configuration for the measurement periods.

Table 2. Average voltage decrease as a function of configuration (Amargosa Valley, NV).

\begin{tabular}{cccc}
\hline Measurement Period & $\begin{array}{c}\text { Average Voltage } \\
\text { Decrease- Tyvex }^{\text {TM }}\end{array}$ & $\begin{array}{c}\text { Average Voltage } \\
\text { Decrease - Mylar }\end{array}$ & $\begin{array}{c}\text { Voltage Difference } \\
\text { (TB - MB) }\end{array}$ \\
\hline $4 / 13-5 / 16 / 2006$ & 87 & 93 & -6 \\
$5 / 16-6 / 16 / 2006$ & 80 & 81 & -1 \\
$6 / 16-7 / 18 / 2006$ & 93 & 89 & 4 \\
$7 / 18-8 / 22 / 2006$ & 98 & 97 & 1 \\
$4 / 13-7 / 18 / 2006$ & 256 & 245 & 11 \\
\hline
\end{tabular}

Table 3. Average voltage decrease as a function of configuration (Las Vegas, NV).

\begin{tabular}{cccc}
\hline Measurement Period & $\begin{array}{c}\text { Average Voltage } \\
\text { Decrease- Tyvex }^{\text {TM }}\end{array}$ & $\begin{array}{c}\text { Average Voltage } \\
\text { Decrease - Mylar }\end{array}$ & $\begin{array}{c}\text { Voltage Difference } \\
\text { (TB - MB) }\end{array}$ \\
\hline $4 / 13-5 / 15 / 2006$ & 77 & 78 & -1 \\
$5 / 15-6 / 16 / 2006$ & 73 & 77 & -4 \\
$6 / 16-7 / 18 / 2006$ & 71 & 76 & -5 \\
$7 / 18-8 / 22 / 2006$ & 75 & 79 & -4 \\
$4 / 13-7 / 18 / 2006$ & 215 & 245 & -30 \\
\hline
\end{tabular}


In general, the average voltage decrease between the configurations showed inconsistent and illogical results, i.e. the voltage decrease from gamma only (Mylar) was greater than the combined effect of gamma plus Rn $\left(\right.$ Tyvex $^{\mathrm{TM}}$ ), suggesting that there was an additional factor contributing to the voltage decrease measured by those E-PERM® sealed in Mylar® bags. Due to these results, use of this method of determining the contribution of ambient gamma exposure to Rn concentration measurements was suspended pending discussions with the system manufacturer. After review of the data, the system manufacturer recommended that activated charcoal packets be placed in the Mylar ${ }^{\circledR}$ bags with the E-PERM ${ }^{\circledR}$ to absorb any "residual” Rn trapped in the bag at the time of sealing.

Table 4 presents a comparison of the average voltage decrease for E-PERM ${ }^{\circ} \mathrm{S}$ in Tyvex $^{\mathrm{TM}}$ bags with those for the E-PERM®s with activated charcoal, in the Mylar ${ }^{\circledR}$ bags. The consistency in the average monthly voltage difference indicated that the use of activated charcoal could be a viable technique for calculating the effect of ambient gamma on E-PERM ${ }^{\circledR} \mathrm{Rn}$ measurements.

Table 4. Effect of the use of activated charcoal on average voltage decrease (Amargosa Valley).

\begin{tabular}{lllll}
\hline \multicolumn{1}{c}{ Measurement Period } & \multicolumn{1}{c}{$\begin{array}{c}\text { Average Voltage } \\
\text { Decrease- Tyvex }\end{array}$} & $\begin{array}{c}\text { Average Voltage Decrease } \\
\text { - Mylar/AC }\end{array}$ & $\begin{array}{c}\text { Voltage Difference } \\
\text { (TB - MB) }\end{array}$ \\
\hline $11 / 03-12 / 11 / 2006$ & 114 & 97 & 17 & 17 \\
$12 / 01 / 2006-1 / 25 / 2007$ & 119 & 102 & 15 \\
$1 / 25-02 / 20 / 2007$ & 77 & 62 & 17 \\
$11 / 03 / 2006-2 / 20 / 2007$ & 320 & 303 & 17 \\
\hline
\end{tabular}

However, the average voltage decrease measured for the quarterly E-PERMS ${ }^{\circledR}$ suggested an additional, but unidentified problem still existed. This uncertainty, coupled with the operational difficulties associated with attempting to seal the Mylar bag containing E-PERMS ${ }^{\circledR}$ in the field, or "opening” the E-PERMS ${ }^{\circledR}$ while sealed in the Mylar bag, negatively impacted the effectiveness of this technique. Because of these difficulties and the unexplained smaller-thanexpected quarterly voltage decrease, consideration of using E-PERM® in Mylar bags to measure the effect of the ambient gamma exposure rate on the Rn concentration measurement was terminated in favor of using the exposure rate monitoring capability at the adjacent CEMP station in Amargosa Valley.

\section{Continuous Rn Monitoring System}

\section{AlphaGUARD System Environmental Sensors Performance}

To assess the accuracy of the environmental sensors of the AGS, and to determine if the conditions in the environmental enclosure might be significantly different from ambient conditions, mean temperature, barometric pressure and relative humidity values were calculated for specific periods and compared with the same data from the CEMP station in Amargosa Valley. The criterion selected was whether the difference between the mean AGS value for the parameter and the mean CEMP value for the parameter fell outside the range of Initial Calibration Uncertainty (ICU) value for the AGS parameter sensor as provided by the manufacturer. The ICU values for temperature, barometric pressure, and relative humidity ( $\mathrm{rH}$ ) are $+/-2.5^{\circ} \mathrm{F},+/-0.1$ ” $\mathrm{Hg}$, and $+/-3$ percent $\mathrm{rH}$, respectively (Genitron, Inc., 1998). The results of these comparisons are presented in Tables 5, 6, and 7. 
Table 5. Mean temperature comparison, CEMP and AGS

\begin{tabular}{lccc}
\hline \multicolumn{1}{c}{.Measurement Period } & $\begin{array}{c}\text { CEMP Mean } \\
\text { Temperature }\left({ }^{\circ} \mathrm{F}\right)\end{array}$ & $\begin{array}{c}\text { AGS Mean } \\
\text { Temperature }\left({ }^{\circ} \mathrm{F}\right)\end{array}$ & $\begin{array}{c}\text { Measurement Delta } \\
(\text { AGS - CEMP) }\end{array}$ \\
\hline $4 / 4-5 / 8 / 2007$ & 66.7 & 69.2 & 2.5 \\
$5 / 9-6 / 6 / 2007$ & 79.5 & 82.2 & 2.7 \\
$6 / 7-7 / 10 / 2007$ & 86.5 & 91.0 & 4.5 \\
$7 / 11-8 / 7 / 2007$ & 89.9 & 91.4 & 1.5 \\
$8 / 8-9 / 4 / 2007$ & 89.3 & 93.1 & 3.8 \\
$9 / 5-10 / 2 / 2007$ & 74.9 & 77.0 & 2.1 \\
$10 / 3-11 / 3 / 2007$ & 63.6 & 65.8 & 2.2 \\
$11 / 4-12 / 04 / 2007$ & 53.6 & 54.8 & 1.2 \\
$12 / 5 / 2007-1 / 08 / 2008$ & 41.6 & 43.3 & 1.7 \\
\hline
\end{tabular}

Table 6. Mean barometric pressure comparison, CEMP and AGS.

\begin{tabular}{lccc}
\hline \multicolumn{1}{c}{$\begin{array}{c}\text { Measurement } \\
\text { Period }\end{array}$} & $\begin{array}{c}\text { CEMP Mean Barometric } \\
\text { Pressure ("Hg)) }\end{array}$ & $\begin{array}{c}\text { AGS Mean } \\
\text { Barometric Pressure ( "Hg)) }\end{array}$ & $\begin{array}{c}\text { Measurement Delta } \\
\text { (AGS - CEMP) }\end{array}$ \\
\hline $4 / 4-5 / 8 / 2007$ & 27.3 & 27.4 & 0.1 \\
$5 / 9-6 / 6 / 2007$ & 27.3 & 27.3 & 0.0 \\
$6 / 7-7 / 10 / 2007$ & 27.3 & 27.3 & 0.0 \\
$7 / 11-8 / 7 / 2007$ & 27.4 & 27.3 & 0.1 \\
$8 / 8-9 / 4 / 2007$ & 27.3 & 27.4 & 0.1 \\
$9 / 5-10 / 2 / 2007$ & 27.4 & 27.5 & 0.1 \\
$10 / 3-11 / 3 / 2007$ & 27.5 & 27.5 & 0.0 \\
$11 / 4-12 / 4 / 2007$ & 27.5 & 27.5 & 0.0 \\
$12 / 5 / 2007-1 / 08 / 2008$ & 27.5 & 27.6 & 0.1 \\
\hline
\end{tabular}

Table 7. Mean relative humidity comparison, CEMP and AGS.

\begin{tabular}{lccc}
\hline $\begin{array}{c}\text { Measurement } \\
\text { Period }\end{array}$ & $\begin{array}{c}\text { CEMP Mean } \\
\text { Relative Humidity (\%) }\end{array}$ & $\begin{array}{c}\text { AGS Mean } \\
\text { Relative Humidity (\%) }\end{array}$ & $\begin{array}{c}\text { Measurement Delta } \\
\text { (AGS - CEMP) (\%) }\end{array}$ \\
\hline $4 / 4-5 / 8 / 2007$ & 21 & 21 & 0 \\
$5 / 9-6 / 6 / 2007$ & 12 & 12 & 0 \\
$6 / 7-7 / 10 / 2007$ & 10 & 10 & 0 \\
$7 / 11-8 / 7 / 2007$ & 20 & 19 & -1 \\
$8 / 8-9 / 4 / 2007$ & 18 & 18 & 0 \\
$9 / 5-10 / 2 / 2007$ & 26 & 25 & -1 \\
$10 / 3-11 / 3 / 2007$ & 26 & 27 & -1 \\
$11 / 4-12 / 4 / 2007$ & 34 & 33 & -1 \\
$12 / 5-1 / 8 / 2008$ & 45 & 41 & -4 \\
\hline
\end{tabular}


The comparison indicate that the difference between the AGS and the CEMP mean barometric pressure values for the measurement periods were within the ICU value for the AGS. Measurement of $\mathrm{rH}$ showed a similar trend with the difference in mean values falling within the ICU values for eight out of nine periods. The difference between the values for ninth measurement period was slightly above the ICU value, (4 versus 3 percent).

The mean temperature, measured by the AGS, was consistently higher than that calculated for the CEMP station. The differences between the AGS and the CEMP mean temperature values exceeded the ICU for temperature three out of nine measurement periods, with the differences exceeding the ICU by more than 50 percent two out of three times.

To determine if there were significant differences between the data collected by the AGS and that collected at the CEMP station, both quantitative and qualitative evaluations were conducted to determine the statistical and practical significance of the differences. These analyses were performed on paired data from April 2007 to January 2008. The following presents a summary of these analyses. A detailed discussion of the analyses is presented in Appendix B.

These analyses focused on the concept of practical rather than statistical significance. Statistical significance was determined through a combination of graphical and simple descriptions of the differences. For this analysis, the difference between the two instruments versus the mean value was plotted to determine if the AGS was less accurate at different absolute values. For example, it was found that the AGS reported temperatures as much as $41^{\circ} \mathrm{F}\left(5^{\circ} \mathrm{C}\right)$ higher than the CEMP station at higher temperatures. The difference in measurements as a function of time of year indicated that the two systems behaved differently in summer than in winter.

To evaluate the practical significance of the differences, the 95 percent confidence interval of the mean difference was plotted. This interval was then compared with a difference of 0.0 , which represents perfect agreement between the instruments. If the line of perfect agreement fell within the 95 percent confidence interval, it was concluded that there is no practical difference in data from the two instruments. However, even if the line of perfect agreement falls outside of the 95 percent confidence interval, the relative magnitude of the difference may be small enough to be practically insignificant.

The results of the analyses found the following:

\section{Temperature}

- Temperature recorded by the AGS tended to be higher overall.

- The AGS was least accurate in July and most accurate in January

- The AGS was less accurate at higher temperatures, consistent with the accuracy in July.

- The difference between the two instruments may have not been practically significant.

\section{Relative Humidity}

- Overall, relative humidity was lower in the AGS than in the CEMP station.

- The AGS was least accurate in December and most accurate in June.

- The AGS was less accurate at higher relative humidity. 
- The difference between the two instruments was practically significant.

\section{Barometric Pressure}

- Overall, the pressure recorded in the AGS was higher than that recorded by the CEMP station.

- The AGS was least accurate in January and was most accurate in May.

- These differences may have been practically insignificant.

The results of these analyses indicate that the meteorological sensors in the AGS, as deployed, were representative of ambient temperature and relative humidity conditions. The difference between the AGS and CEMP barometric pressure data suggests that the environmental enclosure had an effect on the measured barometric pressure or there was an inherent difference between the two measurement systems.

\section{Ambient Rn-222 Measurements, Amargosa Valley, Nevada}

Ambient Rn monitoring to establish baseline concentrations was initiated on April 3, 2007. Between April 2007 and February 2008, approximately nine months of ambient $\mathrm{Rn}$ concentration data were collected utilizing both passive integrating and continuous $\mathrm{Rn}$ monitoring systems.

\section{Continuous Rn Monitoring (AGS)}

The AGS was set up to record average hourly Rn concentrations. However, due to a finite data storage capacity, Rn monitoring data were down loaded approximately every four weeks. Figure 4 shows the variability in the distribution of monthly ambient Rn concentrations. The distribution of average hourly ambient Rn concentrations varied widely over any given period, with concentrations ranging from less than $0.05 \mathrm{pCi} / \mathrm{l}$ to more than $1.40 \mathrm{pCi} / \mathrm{l}$. The distribution of the data around the medians suggests that ambient Rn concentrations were low, not normally distributed, and were skewed by higher concentrations. The average hourly Rn concentration for the period April 2007 through January 2008 was $0.23+/$ 0.17 pCi/l.

Due to failure of a power transformer, the AGS system was off line from late February through late March 2008. The AGS system was briefly redeployed between late March and early April, when it taken off-line for evaluating whether data collected with it could be transmitted automatically from remote locations.

\section{$\underline{\text { Real-time Rn Data Transmission }}$}

The AGS was off-line in April 2008 to evaluate and demonstrate the feasibility of coupling the system with a Campbell Scientific, Inc. data logger (Model \# CR 1000) (Campbell Scientific, Inc., 2009) and transmitting the data via wireless internet to the Western Regional Climatic Center (WRCC), operated by DRI for the National Oceanic and Atmospheric Administration (NOAA). DRI faculty met and worked with Campbell Scientific staff to develop proper coding for the binary formatted output sent from the AGS unit, and to match the AGS output data rate with the expected data logger input rate. Additional code in the data logger was required to decode and transform the binary data format from the AGS to data values that the data logger could record and then use in subsequent computations. Successful interface was established in February 2009 (Campbell Scientific Inc, 2009). 


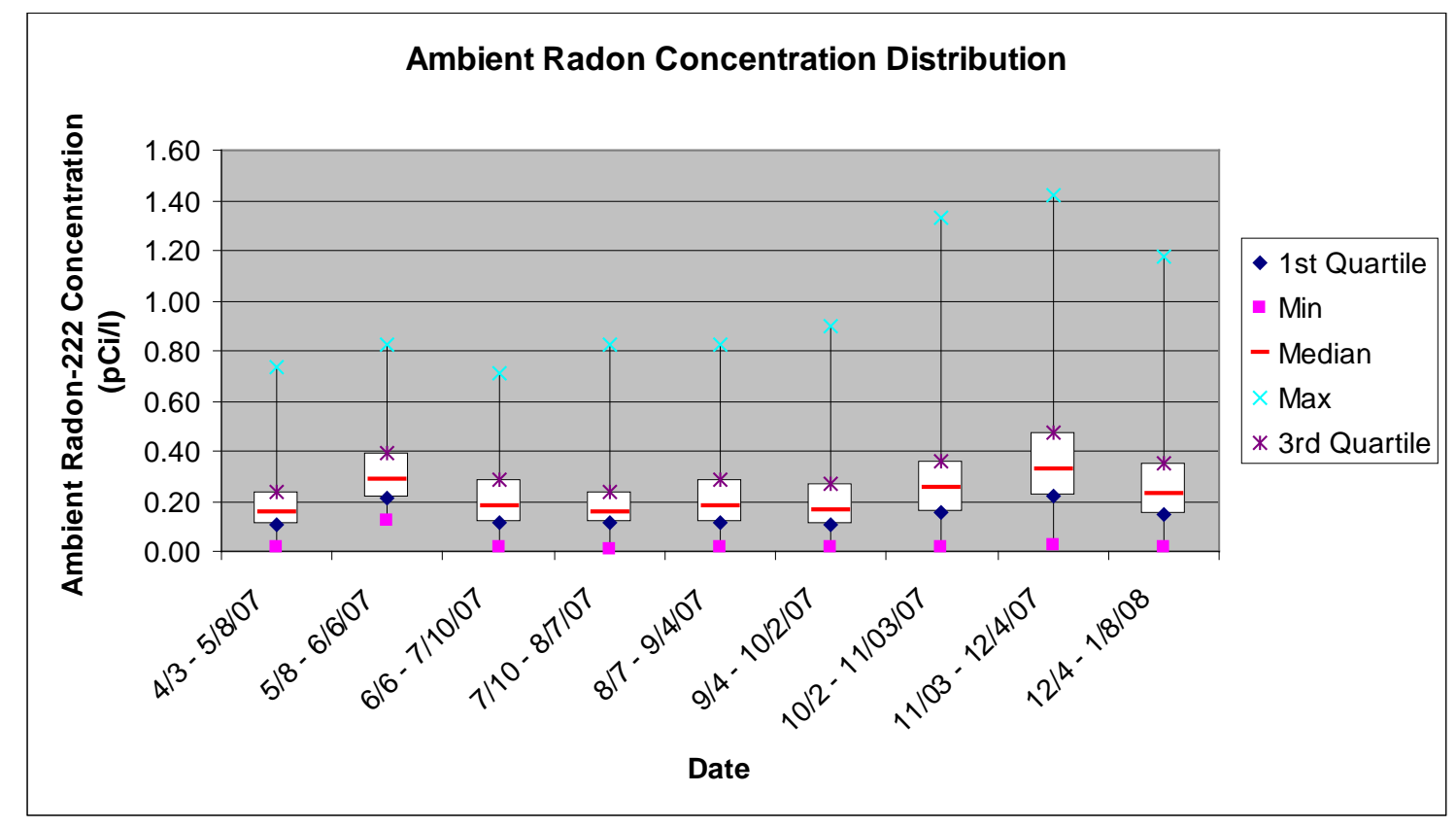

Figure 4. Distribution of ambient Rn concentrations.

The AGS was deployed at the CEMP station in Amargosa Valley and linked to the Campbell Scientific data logger at that site in early March of 2009. The integrated system transmitted data continuously from March 11, 2009 to April 7, 2009. During this period, DRI faculty randomly selected one-week of data for comparison to determine if the transmitted data was consistent that in the AGS memory. The comparison determined the two sets of data were equivalent. Data transmission was interrupted on April 7 when an unintentional change of the data rate at the AGS unit caused the data to be lost. This problem was undetected until May 6, 2009 when it was identified and resolved. Data transmission and collection during the period prior to April 7, 2009 was 100 percent.

The integrated system operated continuously between May 6 and July 7, 2009 except for two data gaps. During this period, DRI faculty identified two data gaps, one between $1700 \mathrm{hrs}$ and 2220 hrs on June 6 and the second between 1450 hrs on July 4 and 0150 hrs on July 6, 2009. Retrieval of Rn monitoring data from the AGS indicated that data collection was at 100 percent for the monitoring period. The data gap was attributed to an undetermined transmission problem. The remotely transmitted data indicated that hourly ambient Rn concentrations are consistent, with average concentrations ranging between $0.23+/-0.16 \mathrm{pCi} / \mathrm{l}$ for the March-April period to $0.20+/-00.12 \mathrm{pCi} / \mathrm{l}$ for the June-July period.

\section{$\underline{\left.\text { Ambient Rn Monitoring (E-PERMS }{ }^{\circledR}\right)}$}

Rn monitoring using E-PERMS® began in April 2007 and continued into July 2009. E-PERMS ${ }^{\circledR}$ were deployed in sets of three for both short-term and long-term deployment periods. Short-term deployment ranged between 25 to 63 days, with the majority (93 percent) of deployment periods falling within a period of 26 -38 days. Long-term deployment periods ranged between 90 - 126 days, with the majority (75 percent) falling within a 90-96 day window. Table 8 presents the average Rn concentration measured for each of the deployment periods. 
Table 8. Average Rn concentration by monitoring period.

\begin{tabular}{|c|c|c|}
\hline Monitoring Period & $\begin{array}{l}\text { Average Short-term Rn Conc. } \\
\text { Measurements (pCi/l) } \\
\text { (E-PERM®) }\end{array}$ & $\begin{array}{l}\text { Average Long-term Rn Conc. } \\
\text { Measurements } \\
\left.\text { (pCi/l) (E-PERM }{ }^{\circledR}\right)\end{array}$ \\
\hline $4 / 3-5 / 8 / 2007$ & $0.3+/-0.1$ & \\
\hline $5 / 8-6 / 5 / 2007$ & $0.3+/-0.0$ & \\
\hline $6 / 5-7 / 10 / 2007$ & $0.3+/-0.1$ & \\
\hline $7 / 10-8 / 7 / 2007$ & $0.2+/-0.1$ & $0.2+/-0.1$ \\
\hline $8 / 7-9 / 4 / 2007$ & $0.2+/-0.1$ & \\
\hline $9 / 4-10 / 2 / 2007$ & $0.2+/-0.1$ & \\
\hline $10 / 2-12 / 4 / 2007$ & $0.3+/-0.1$ & \\
\hline $12 / 4 / 2007-1 / 8 / 2008$ & $0.4+/-0.1$ & $0.3+/-0.1$ \\
\hline $1 / 8-2 / 6 / 2008$ & $0.3+/-0.1$ & \\
\hline $2 / 6-3 / 4 / 2008$ & $0.4+/-0.1$ & \\
\hline $3 / 5-4 / 8 / 2008$ & $0.3+/-0.1$ & $0.3+/-0.1$ \\
\hline $4 / 8-5 / 6 / 2008$ & $0.2+/-0.1$ & \\
\hline $5 / 6-6 / 3 / 2008$ & $0.2+/-0.1$ & \\
\hline $6 / 3-7 / 1 / 2008$ & $0.2+/-0.1$ & $0.2+/-0.1$ \\
\hline $7 / 8-8 / 5 / 2008$ & $0.2+/-0.1$ & \\
\hline $8 / 5-9 / 2 / 2008$ & $0.2+/-0.0$ & \\
\hline $9 / 2-10 / 7 / 2008$ & $0.2+/-0.1$ & $0.3+/-0.1$ \\
\hline $10 / 7-11 / 4 / 2008$ & $0.3+/-0.1$ & \\
\hline $11 / 4-12 / 12 / 2008$ & $0.4+/-0.1$ & \\
\hline $12 / 12 / 2008-1 / 06 / 2009$ & $0.4+/-0.1$ & $0.3+/-0.1$ \\
\hline $1 / 6-2 / 3 / 2009$ & $0.5+/-0.2$ & \\
\hline $2 / 3-3 / 3 / 2009$ & $0.3+/-0.1$ & \\
\hline $3 / 3-4 / 7 / 2009$ & $0.3+/-0.1$ & $0.3+/-0.1$ \\
\hline $4 / 7-5 / 6 / 2009$ & $0.3+/-0.1$ & \\
\hline $5 / 6-6 / 9 / 2009$ & $0.3+/-0.1$ & \\
\hline $6 / 9-7 / 7 / 2009$ & $0.3+/-0.1$ & $0.2+/-0.1$ \\
\hline
\end{tabular}

The mean average Rn concentration for April 2007 to July 2009, as determined by E-PERMS ${ }^{\circledR}$ deployed over both the short and long-term, was $0.3+/-0.1 \mathrm{pCi} / \mathrm{l}$. Figures 5 and 6 show the distribution of average Rn-222 concentrations as a function of monitoring duration. Average "short-term" Rn concentration measurements ranged from 0.2-0.5 pCi/l, while average "long-term” Rn concentration measurements showed less variability, ranging from 0.2 to $0.3 \mathrm{pCi} / \mathrm{l}$.

\section{Comparison of Ambient Rn-222 Measurements}

Comparison of the average Rn concentration data from the AGS and the short-term EPERMS showed a high degree of agreement, as presented in Table 9. Average Rn concentrations, as measured by both systems, ranged from approximately 0.2 to $0.4 \mathrm{pCi} / \mathrm{l}$. This range of concentrations is consistent with the average $\mathrm{Rn}$ concentration of $0.34 \mathrm{pCi} / \mathrm{l}$ reported for the period 1991 to 1995 for onsite monitoring stations near Yucca Mountain (TESS, 1999). In addition, these data were consistent with the ambient Rn measurement of $0.30 \mathrm{pCi} / \mathrm{l}$ reported for a location in the general area of Amargosa Valley during the early 1990s based on measurements by the State of Nevada Bureau of Mines and Geology (Price, 1994). 


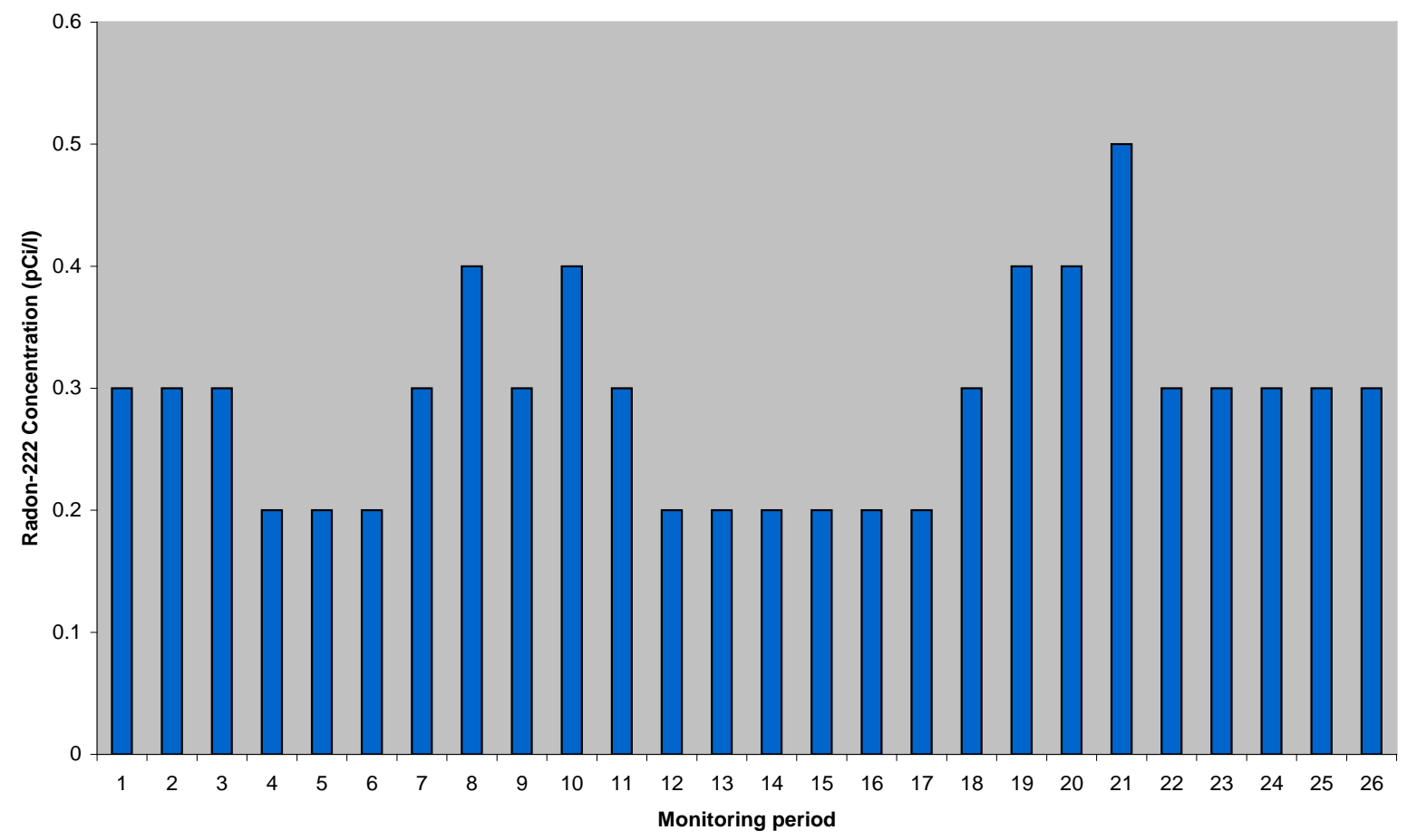

Figure 5. Average ambient Rn concentration - short-term from the EPERMS.

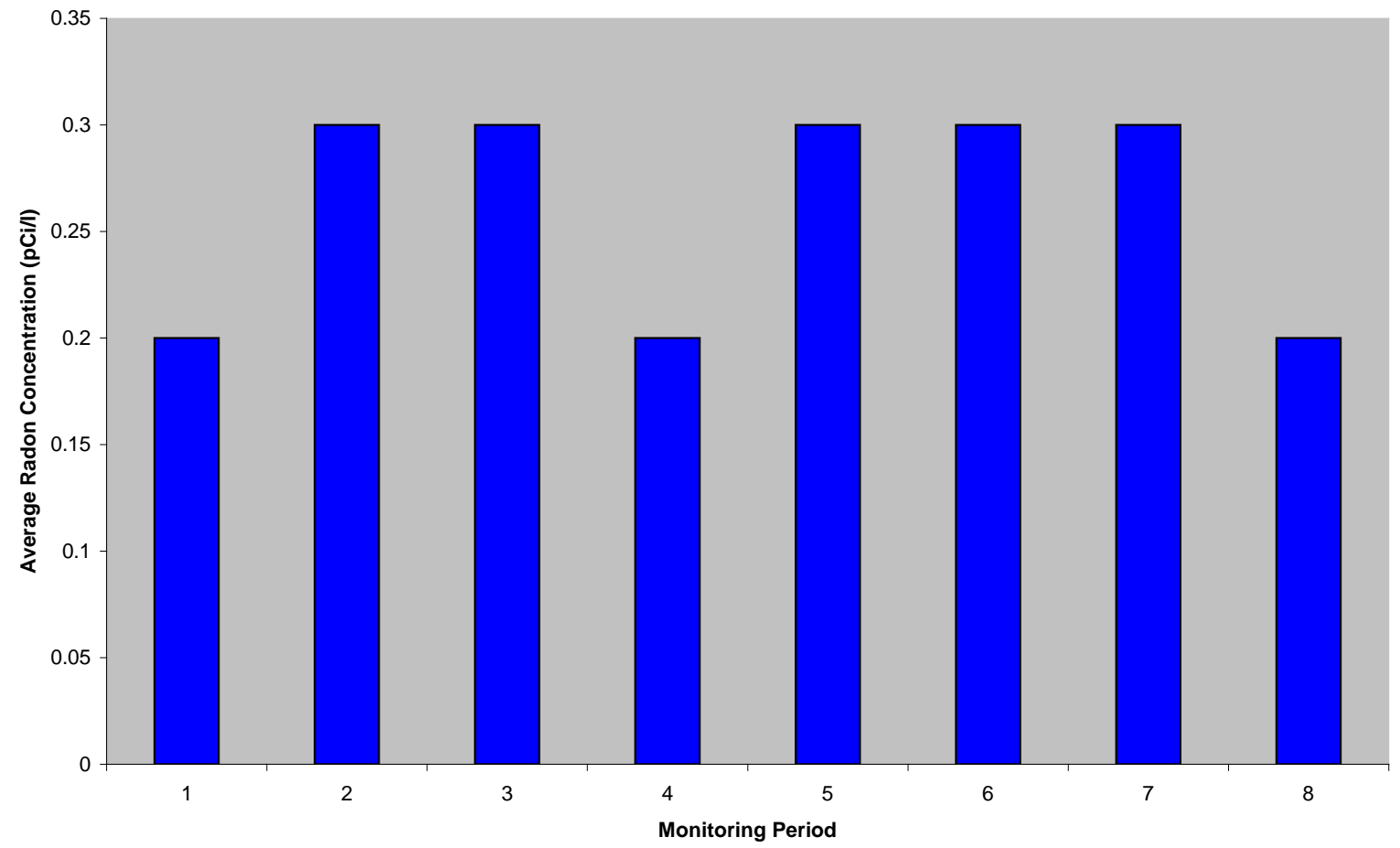

Figure 6. Ambient Rn concentrations - long-term from the EPERMS. 
Table 9. Average Rn-222 concentration comparison. (pCi/l)

\begin{tabular}{lcc}
\hline \multicolumn{1}{c}{ Monitoring Period } & $\begin{array}{c}\text { Average Rn Conc. (pCi/l) } \\
(\text { E-PERM®) }\end{array}$ & $\begin{array}{c}\text { Average Rn Conc. (pCi/l) } \\
(\text { AGS) }\end{array}$ \\
\hline $4 / 3-5 / 8 / 2007$ & $0.3+/-0.1$ & $0.18+/-0.12$ \\
$5 / 8-6 / 5 / 2007$ & $0.3+/-0.0$ & $0.21+/-0.13^{++}$ \\
$6 / 5-7 / 10 / 2007$ & $0.3+/-0.1$ & $0.21+/-0.12$ \\
$7 / 10-8 / 7 / 2007$ & $0.2+/-0.1$ & $0.19+/-0.12$ \\
$4 / 3-8 / 7 / 2007(\mathrm{Q})$ & $0.2+/-0.1$ & $0.20+/-0.12$ \\
$8 / 7-9 / 4 / 2007$ & $0.2+/-0.1$ & $0.21+/-0.13$ \\
$9 / 4-10 / 2 / 2007$ & $0.2+/-0.1$ & $0.20+/-0.13$ \\
$10 / 2-12 / 4 / 2007$ & $0.3+/-0.1$ & $0.33+/-0.19$ \\
$12 / 4 / 2007-1 / 8 / 2008$ & $0.4+/-0.1$ & $0.36+/-0.25$ \\
$10 / 2 / 2007-1 / 8 / 2008$ (Q) & $0.3+/-0.1$ & $0.34+/-0.19$ \\
$1 / 8 / 2008-2 / 6 / 2008$ & $0.3+/-0.1$ & $0.28+/-0.18^{* *}$ \\
$2 / 6 / 2008-3 / 4 / 2008$ & $0.4+/-0.1$ & $\mathrm{~N} / \mathrm{A}^{* *}$ \\
$3 / 5 / 2008-4 / 8 / 2008$ & $0.3+/-0.1$ & $0.25+/-0.17^{* *}$ \\
$1 / 8 / 2008-4 / 8 / 2008$ (Q) & $0.3+/-0.1$ & $\mathrm{~N} / \mathrm{A}^{* *}$ \\
\hline${ }^{++}$Unexplained time/data gap. & & \\
${ }^{* * *}$ Incomplete data set; non-detector related equipment failure. & \\
\hline
\end{tabular}

A review of the AGS data records indicates that the system lost data for a period of 32 consecutive hours between May 9 and 10, 2007. No apparent reason for this data gap could be identified. The systems data collection efficiency remained at 100 percent between the time data collection resumed on May 10, 2007 through January 29, 2008 when the failure of a nondetector-related piece of equipment resulted in system shut-down and loss of data.

\section{Comparison of AGS Environmental Parameter Measurements with Ambient Rn-222 Concentration Measurements.}

To identify the potential relationship between individual local meteorological parameters that could potentially affect Rn concentrations, i.e., temperature, barometric pressure, and relative humidity, and ambient Rn concentration, simple correlation analyses were performed. Correlation coefficients (r) were calculated for each parameter, for a month and for a day within that month. The results indicated a weak, variable correlation between any one parameter and ambient Rn concentration. These correlations are presented in Tables 10 and 11.

A consistent, but variable, positive correlation was found between average hourly Rn concentration and relative humidity for the daily and monthly periods, while a consistent, but weak, inverse relationship was found between temperature and Rn concentrations. A very weak, variable correlation was found between barometric pressure and ambient Rn concentration. Such relationships are consistent with those previously identified for ambient Rn measurements made during the site characterization for Yucca Mountain (TESS, 1998). Figures A-1 through A-12 in Appendix A present graphical summaries of these relationships for selected time periods. The concentration of $\mathrm{Rn}$ in air is the result of several interactive processes. These figures do not reveal a clear, strong relationship, either positive or negative, between ambient Rn concentration and any individual meteorological parameter. However, a weak diurnal inverse relationship between Rn concentration and temperature was suggested (Figure 8). 
Table 10. Correlation coefficients for average monthly ambient Rn-222 concentration and AGS-measured average monthly temperature, pressure and relative humidity.

\begin{tabular}{lccc}
\hline & \multicolumn{3}{c}{ Correlation Coefficient $(\mathrm{r})$} \\
\hline \multicolumn{1}{c}{ Measurement Period } & Temperature & Pressure & Relative Humidity \\
$4 / 3-5 / 8 / 2007$ & -0.24 & 0.09 & 0.18 \\
$5 / 8-6 / 5 / 2007$ & -0.68 & 0.19 & 0.44 \\
$6 / 5-07 / 10 / 2007$ & -0.54 & 0.17 & 0.26 \\
$7 / 10-8 / 7 / 2007$ & -0.57 & 0.23 & 0.31 \\
$8 / 7-9 / 4 / 2007$ & -0.66 & 0.10 & 0.24 \\
$9 / 4-10 / 2 / 2007$ & -0.34 & 0.10 & 0.00 \\
$10 / 2-12 / 4 / 2007$ & -0.40 & -0.06 & 0.37 \\
$12 / 4-1 / 2008 / 2007$ & -0.31 & 0.04 & 0.22 \\
\hline
\end{tabular}

Table 11. Correlation coefficients for average daily ambient Rn-222 concentration and AGS-measured average daily temperature, pressure and relative humidity.

\begin{tabular}{lccc}
\hline \multicolumn{1}{c}{ Date } & Temperature & $\begin{array}{c}\text { Correlation Coefficient (r) } \\
\text { Pressure }\end{array}$ & Relative Humidity \\
\hline $4 / 16 / 2007$ & -0.26 & -0.16 & 0.19 \\
$5 / 15 / 2007$ & -0.89 & 0.28 & 0.89 \\
$6 / 15 / 2007$ & -0.82 & 0.28 & 0.73 \\
$7 / 15 / 2007$ & -0.82 & -0.09 & 0.39 \\
$8 / 15 / 2007$ & -0.81 & 0.58 & 0.90 \\
$9 / 15 / 2007$ & -0.70 & 0.56 & 0.79 \\
$10 / 15 / 2007$ & -0.79 & 0.57 & 0.85 \\
$11 / 15 / 2007$ & -0.34 & -0.19 & 0.31 \\
$12 / 15 / 2007$ & -0.48 & -0.20 & 0.41 \\
\hline
\end{tabular}

To identify potential relationship between temperature $(\mathrm{T})$, pressure $(\mathrm{P})$, and relative humidity ( $\mathrm{rH}$ ), and ambient Rn concentration, a principal component analysis (PCA) was conducted in an attempt to reduce the dimensions of the dataset and evaluate the relative importance of each meteorological variable. The data were scaled to unit variance and rotated to their principal components. Figure 7 show that no one parameter explains most of the variance in $\mathrm{Rn}$. The length of the T vector along the PC1 axis is slightly longer relative to the $\mathrm{P}$ and $\mathrm{H}$ vectors, implying that temperature should explain slightly more of the variance in Rn than either barometric pressure or relative humidity. However, again no one variable was predominant.

Multiple linear regression analyses were performed on combinations of the three meteorological variables, including linear transformations of those variables. Table 12 presents the results of these analyses. Of the 32 models tested, two models $\left(\log (\mathrm{Rn})=\alpha+\beta_{1} \mathrm{~T}+\beta_{2} \log \right.$ $\left.(\mathrm{H}) ; \log (\mathrm{Rn})=\alpha+\beta_{1} \mathrm{~T}+\beta_{2} \log (\mathrm{H})+\beta_{3} \log (\mathrm{P})\right)$ explained the most variation in Rn. However, these models were only marginally better than the equation: $\log (\mathrm{Rn})=\alpha+\beta_{1} \mathrm{~T}$, a simpler model. A stronger relationship between $\mathrm{Rn}$ and temperature is suggested by the principal component analysis above. The relationship between $\log (\mathrm{Rn})$ and $\mathrm{T}$ is shown in Figure 7. 


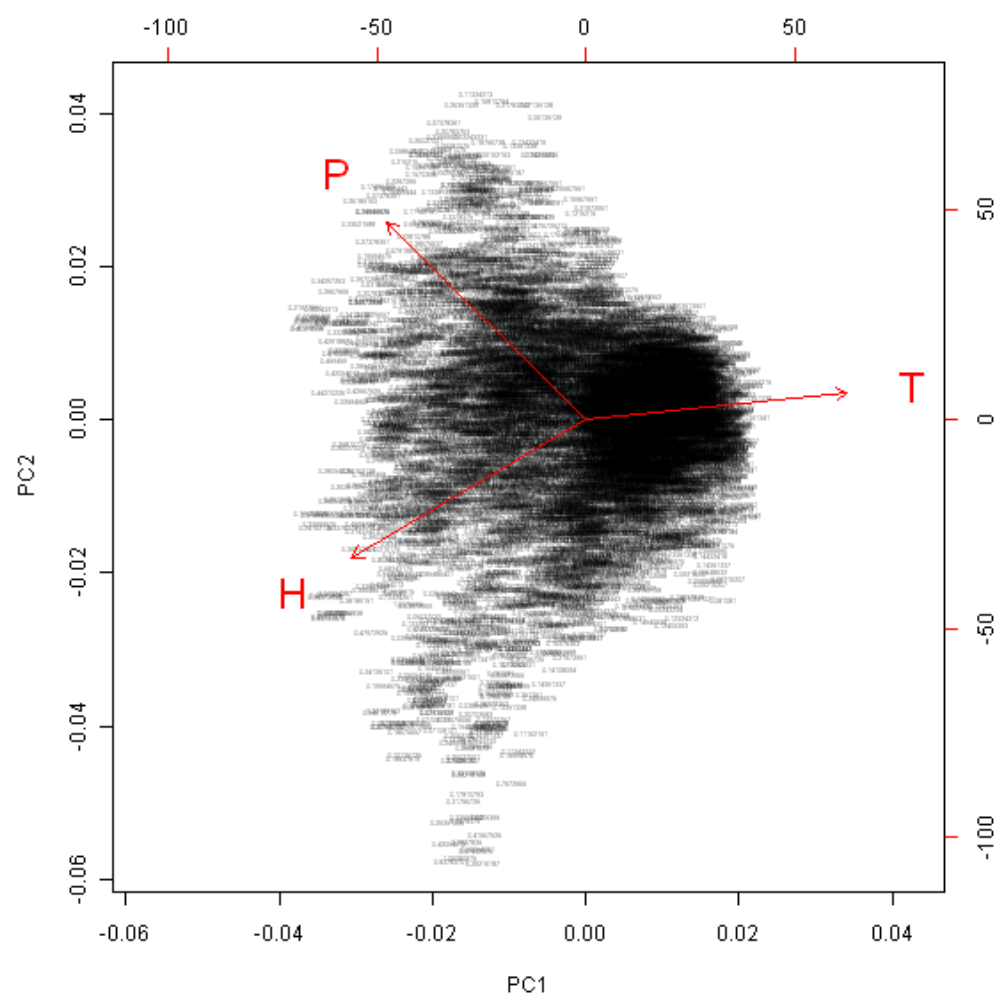

Figure 7. Principal component analysis of pressure, temperature, and humidity.

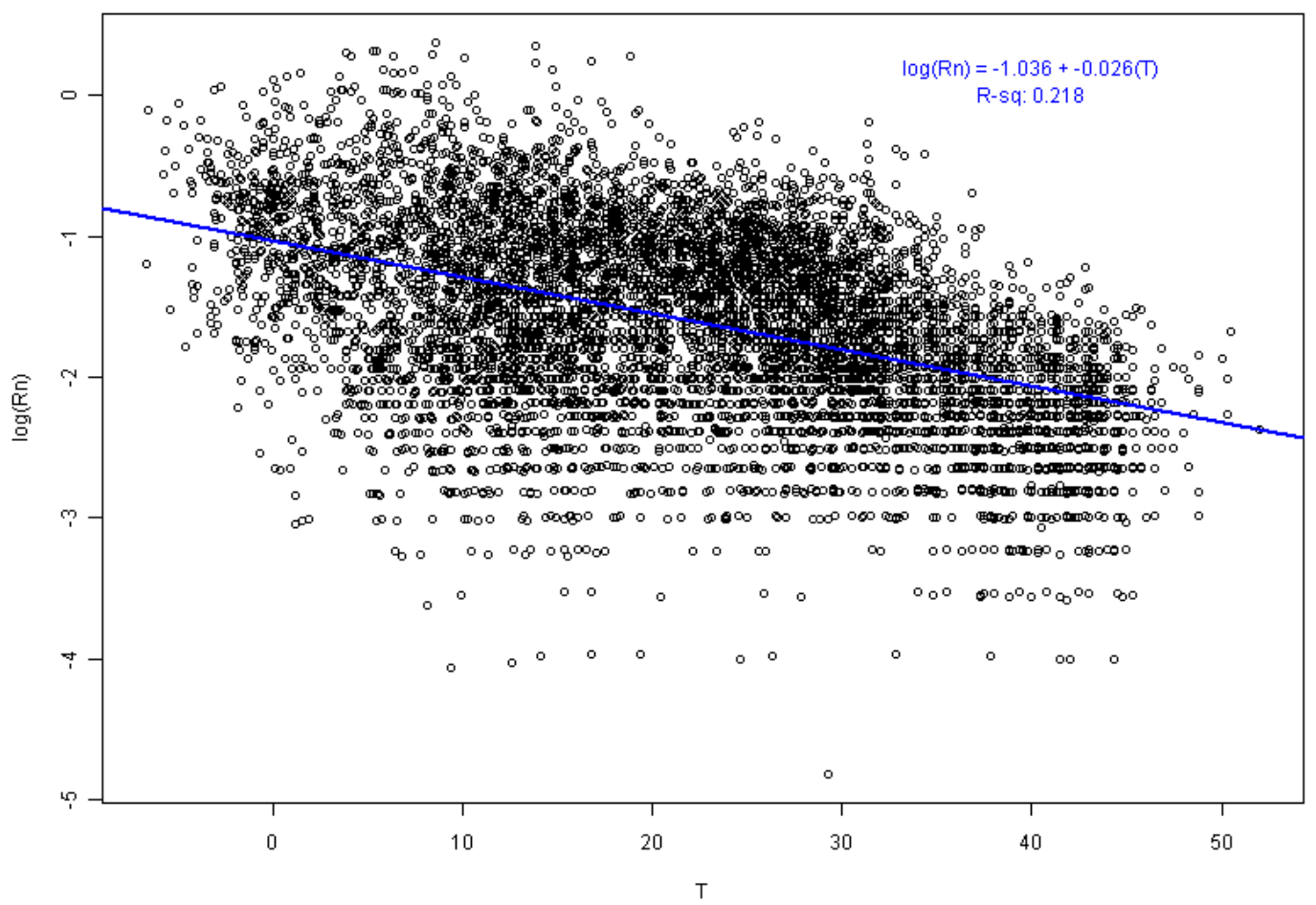

Figure 8. Relationship between log (Rn) and temperature. 
Table 12. Multiple linear regression results.

\begin{tabular}{|c|c|}
\hline Model & $\mathrm{R}^{2}$ \\
\hline $\log (\mathrm{Rn}) \sim \mathrm{T}+\log (\mathrm{H})$ & 0.224 \\
\hline $\log (\mathrm{Rn}) \sim \mathrm{T}+\log (\mathrm{H})+\log (\mathrm{P})$ & 0.224 \\
\hline $\log (\mathrm{Rn}) \sim \mathrm{T}$ & 0.218 \\
\hline $\log (\mathrm{Rn}) \sim \mathrm{T}+\mathrm{H}$ & 0.218 \\
\hline $\log (\mathrm{Rn}) \sim \mathrm{T}+\mathrm{P}$ & 0.218 \\
\hline $\log (\mathrm{Rn}) \sim \mathrm{T}+\mathrm{H}+\mathrm{P}$ & 0.218 \\
\hline $\log (\mathrm{Rn}) \sim \mathrm{T}+\log (\mathrm{P})$ & 0.218 \\
\hline $\mathrm{Rn} \sim \mathrm{T}+\log (\mathrm{H})$ & 0.212 \\
\hline $\mathrm{Rn} \sim \mathrm{T}+\log (\mathrm{H})+\log (\mathrm{P})$ & 0.212 \\
\hline $\mathrm{Rn} \sim \mathrm{T}+\operatorname{inv}(\mathrm{H})+\operatorname{inv}(\mathrm{P})$ & 0.212 \\
\hline $\mathrm{Rn} \sim \mathrm{T}+\mathrm{inv}(\mathrm{H})$ & 0.211 \\
\hline $\mathrm{Rn} \sim \mathrm{T}+\mathrm{H}$ & 0.209 \\
\hline $\mathrm{Rn} \sim \mathrm{T}+\mathrm{H}+\mathrm{P}$ & 0.209 \\
\hline $\mathrm{Rn} \sim \mathrm{T}$ & 0.208 \\
\hline $\mathrm{Rn} \sim \mathrm{T}+\mathrm{P}$ & 0.208 \\
\hline $\mathrm{Rn} \sim \mathrm{T}+\log (\mathrm{P})$ & 0.208 \\
\hline $\mathrm{Rn} \sim \mathrm{T}+\mathrm{inv}(\mathrm{P})$ & 0.208 \\
\hline $\log (\mathrm{Rn}) \sim \log (\mathrm{H})+\log (\mathrm{P})$ & 0.177 \\
\hline $\log (\mathrm{Rn}) \sim \log (\mathrm{H})$ & 0.164 \\
\hline $\mathrm{Rn} \sim \log (\mathrm{H})$ & 0.150 \\
\hline $\mathrm{Rn} \sim \mathrm{H}+\mathrm{P}$ & 0.133 \\
\hline $\log (\mathrm{Rn}) \sim \mathrm{H}+\mathrm{P}$ & 0.133 \\
\hline $\mathrm{Rn} \sim \mathrm{H}+\log (\mathrm{P})$ & 0.133 \\
\hline $\mathrm{Rn} \sim \mathrm{H}+\mathrm{inv}(\mathrm{P})$ & 0.133 \\
\hline $\mathrm{Rn} \sim \operatorname{inv}(\mathrm{H})$ & 0.127 \\
\hline $\mathrm{Rn} \sim \mathrm{H}$ & 0.115 \\
\hline $\log (\mathrm{Rn}) \sim \mathrm{H}$ & 0.108 \\
\hline $\log (\mathrm{Rn}) \sim \mathrm{P}$ & 0.060 \\
\hline $\log (\mathrm{Rn}) \sim \log (\mathrm{P})$ & 0.060 \\
\hline $\mathrm{Rn} \sim \mathrm{P}$ & 0.050 \\
\hline $\mathrm{Rn} \sim \log (\mathrm{P})$ & 0.050 \\
\hline $\operatorname{Rn} \sim \operatorname{inv}(P)$ & 0.050 \\
\hline
\end{tabular}

\section{DISCUSSION AND CONCLUSIONS}

DRI evaluated three passive Rn monitoring system, two integrating and one continuous. Initial evaluation activities showed that each system has distinct functional characteristics that affect the performance of the monitoring system. Throughout the evaluation process and during the monitoring period, one passive system, Radtrak ${ }^{\circledR}$, exhibited unexpected track response characteristics that resulted in a decision not to use the system for data collection. The remaining systems, E-PERM ${ }^{\circledR}$ and AlphaGUARD ${ }^{\circledR}$, were reliable and accurate within their respective system characteristics. However, each exhibited operational characteristics that placed limitations on their use in arid, rural areas. 
E-PERMS ${ }^{\circledR}$, because they are air ionization chambers, require that the effect of ambient gamma on the measurement be taken into account prior to determining Rn concentrations. Measurement of the ambient gamma component using E-PERMS ${ }^{\circledR}$, with and without activated charcoal, was found to be inconsistent and unreliable. To determine the ambient $\mathrm{Rn}$ concentration, use of an ambient gamma measuring system, such as a PIC, was required. In addition, as integrating monitoring devices, E-PERMS ${ }^{\circledR}$ provide only single, time-averaged measurement and required protection from meteorological condition. These systems are designed as a "deploy-and-forget" system that requires no or infrequent, checking during deployment. A review of the response characteristics of the E-PERMS ${ }^{\circledR}$, i.e., voltage decrease per day deployed, was found to be consistent, averaging a 3 volts/day decrease. This consistency allowed for flexibility in the of length of deployment The average Rn concentration calculated for the April 2007 to July 2009 period was 0.3 pCi/l, regardless of length of the deployment period.

The AlphaGUARD ${ }^{\circledR}$ system, as a continuous monitoring system, allows for variable counting periods, either 10 or 60 minutes. The system utilizes a pulse ionization chamber and a series of post processing algorithms. As such, the system allows for the monitoring of diurnal and/or seasonal variations in Rn concentration. In addition, the system also has the capability of monitoring ambient environmental parameters in the immediate vicinity of the system, allowing for the evaluation of Rn concentration as a function of temperature, barometric pressure, and relative humidity. Comparison of mean barometric pressure and relative humidity values based on AGS measurements and those based on measurements made at the CEMP station showed a relatively high degree of agreement, with all but one mean value falling within the initial calibration uncertainty of the AGS sensors. For the AGS mean temperature values, approximately one-third of the values fell outside of the temperature sensor's initial calibration uncertainty, suggesting a bias due to a buildup of heat in the environmental enclosure.

Review of the AGS data for the period April 2007 through January 2008 indicated an overall hourly data collection efficiency of greater than 99.6 percent with only one period of 31 hours not recorded due to unidentified cause(s). For the same period, the AGS internal status system reported that approximately 38 percent of the hourly average Rn measurements were at or below the lower limit of detection. The association of the "at or below lower limit of detection" status indicator with environmental factors was reviewed and no clear association was identified.

The lack of any identified strong correlation between ambient Rn concentration and any one meteorological parameter is consistent with other findings (e.g., Krajny, 2001). This lack of correlation is attributed to the influence of multiple meteorological parameters on ambient $\mathrm{Rn}$ concentrations. The variability of ambient Rn concentrations, as a function of time, has been attributed to turbulent diffusion and dilution because of meteorological conditions, including atmospheric stability (Porstendorfer, 1994, Desideri, 2006).Other studies found a relationship between Rn and temperature, wind speed and direction, and pressure (e.g., Sundal, et al., 2008), though Gundersen and Wanty (1992), suggesting that the effect of temperature may be masked by pressure changes and precipitation. A stronger correlation was suggested for changes in pressure and Rn concentrations and there appeared to be a lag between changes in environmental variables and change in Rn concentration. Hakl et al. (1995) found daily mean concentration to be a function of daily mean temperature with a step-function relationship, and pressure variations were a large factor in predicting Rn concentrations. Sundal et al. (2008) found strong seasonal and diurnal variations caused by air temperature and pressure. Comparison of the average ambient Rn concentrations measured by the two systems in this study showed a high degree of 
consistency. Mean average hourly Rn concentrations ranged between 0.2.and $0.4 \mathrm{pCi} / \mathrm{l}$, with the average E-PERM® Rn concentration falling consistently within the spread of the AGS measurements, i.e., within plus or minus one standard deviation. Analysis of the hourly AGS Rn concentrations in air to environmental parameters showed a weak diurnal inverse correlation with temperature to be the strongest correlation during the deployment in Amargosa Valley.

\section{ACKNOWLEDGEMENTS}

The authors wish to thank personnel of the U.S. Environmental Protection Agency, National Exposure Research Laboratory in Las Vegas for use of their radon chamber for comparison of instruments under controlled radon concentrations. The Community Environmental Monitoring Program (CEMP) station of the DOE, NNSA Nevada Site Office provided a platform for deployment of the instruments and continuous measurements of meteorological parameters for comparison to Rn measurements. The research was performed by DRI under Contract No. DE-AC-06NA 26383 to the DOE, NNSA Nevada Site Office. 


\section{REFERENCES}

Campbell Scientific, 2009. Interfacing AlphaGUARDwith Campbell Scientific’s CR 1000 Datalogger, Application Note, Campbell Scintific Inc.

Desideri, D., C. Roselli, L. Feduzi, and M.A. Meli, 2006. Monitoring the atmospheric stability of using radon concentration measurements: A study in a Central Italy site. Journal of Radioanalytical and Nuclear Chemistry, 270 (3):523-530.

Genitron Instruments GmbH, 1998. AlphaGUARD Portable Radon Monitor: User Manual.

Griffin, M.D., 1994. Active verses Passive Monitoring at the Yucca Mountain Site, Proceedings of the Fifth Annual International Conference on High Level Radioactive Waste Management, American Nuclear Society/American Society of Civil Engineers, Las Vegas, NV.

Gundersen, L.C.S. and R.B. Wanty, 1992. Field Studies of Radon in Rocks, Soils, and Water. CRC, $1^{\text {st }}$ edition.

Hakl, J, I. Csige, I. Hunyadi, A. Varhegyi, and G. Geczy, 1995. Radon transport in fractured porous media-Experimental study in caves. Environment International, 22 (supplement 1 ), pages $433-437$.

Krajny, E., L Osrodka, M. Wojtylak, B. Michalik, and J. Skowronek, 2001. Correlation between the meteorological conditions and the concentration of radionuclides in the ground layer of atmospheric air, NUKLEONIKA, 46 (4), 189-194.

Liu, N., C.D. Sorensen, C.H. Tung, and C.R. Orchard, 1995. Continuous Environmental Radon Monitoring Program At the Yucca Mountain Site Characterization Project_ Proceedings of the Sixth Annual International Conference on High Level Radioactive Waste Management, American Nuclear Society/American Society of Civil Engineers, Las Vegas, NV.

Price, J.G., J.G. Rigby, L. Christensen, R. Hess, D.D. LaPointe, A.R. Ramelli, M. Desilets, R.D. Hopper, T. Kluesner, and S. Marshall, 1994. Radon in Outdoor Air in Nevada, Health Physics, 66(4): 433 - 438.

Porstendorfer, J. G. Butterweck, and A. Reineking, 1994. Daily Variation of the Radon Concentration Indoors and Outdoors and the Influence of Meteorological Parameters. Health Physics, 67 (3):283-287.

Rad Elec, Inc., 2002. E-RERM® System Users Manual, Frederick, Maryland.

Rigby, J.G., J.G. Price, L.G. Christensen, D.D. La Pointe, A.R. Ramelli, M.O. Desilets, R.H. Hess, and S.R. Marshall, 1994. Radon in Nevada, Nevada Bureau of Mines and Geology, University of Nevada, Reno, Bulletin 108.

Sundal, A.V., V. Valen, O. Soldal, and T. Strand, 2008. The influence of meteorological parameters on soil radon levels in permeable glacial sediments. Science of the total environment, v.389, no.2-3, pages 418-428.

TRW Environmental Safety Systems, Inc. (TESS), 1998. Update Report for Ambient Radon at the Yucca Mountain Site, Civilian Radioactive Waste Management System, Management and Operating Contractor. 
TRW Environmental Safety Systems, Inc. (TESS), 1999. Environmental Baseline File: Human Health, Civilian Radioactive Waste Management System, Management and Operating Contractor.

U.S. Department of Energy, 1988. Radiological Monitoring Plan for the NNWSI Project, Office of Civilian Radioactive Waste Management, Nevada Nuclear Waste Storage Investigations Project, Nevada Operations Office, DOE/NV-10576-6.

U.S. Department of Energy, 2002. Final Environmental Impact Statement for a Geologic Repository for the Disposal of Spent Nuclear Fuel and High-Level Radioactive Waste at Yucca Mountain, Nye County, Nevada, Office of Civilian Radioactive Waste Management, DOE/EIS-0250.

U.S. Department of Energy, 2007. Draft Final Environmental Impact Statement for a Geologic Repository for the Disposal of Spent Nuclear Fuel and High-Level Radioactive Waste at Yucca Mountain, Nye County, Nevada, Office of Civilian Radioactive Waste Management, DOE/EIS-0250F-S1D. 
THIS PAGE INTENTIONALLY LEFT BLANK 


\section{APPENDIX A: COMPARISON OF AVERAGE RADON CONCENTRATIONS AND METEOROLOGICAL PARAMETERS}

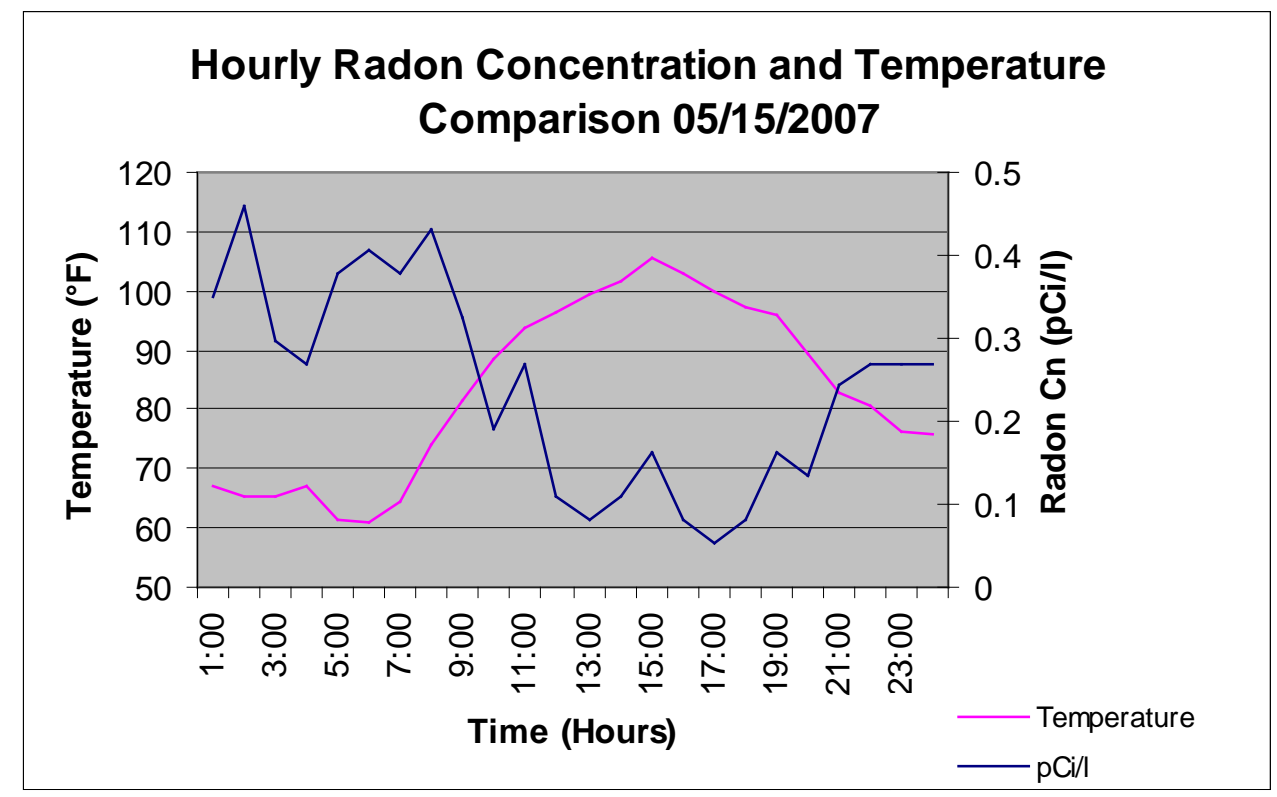

Figure A-1. Hourly AGS Rn concentration and temperature comparison 05/15/2007.

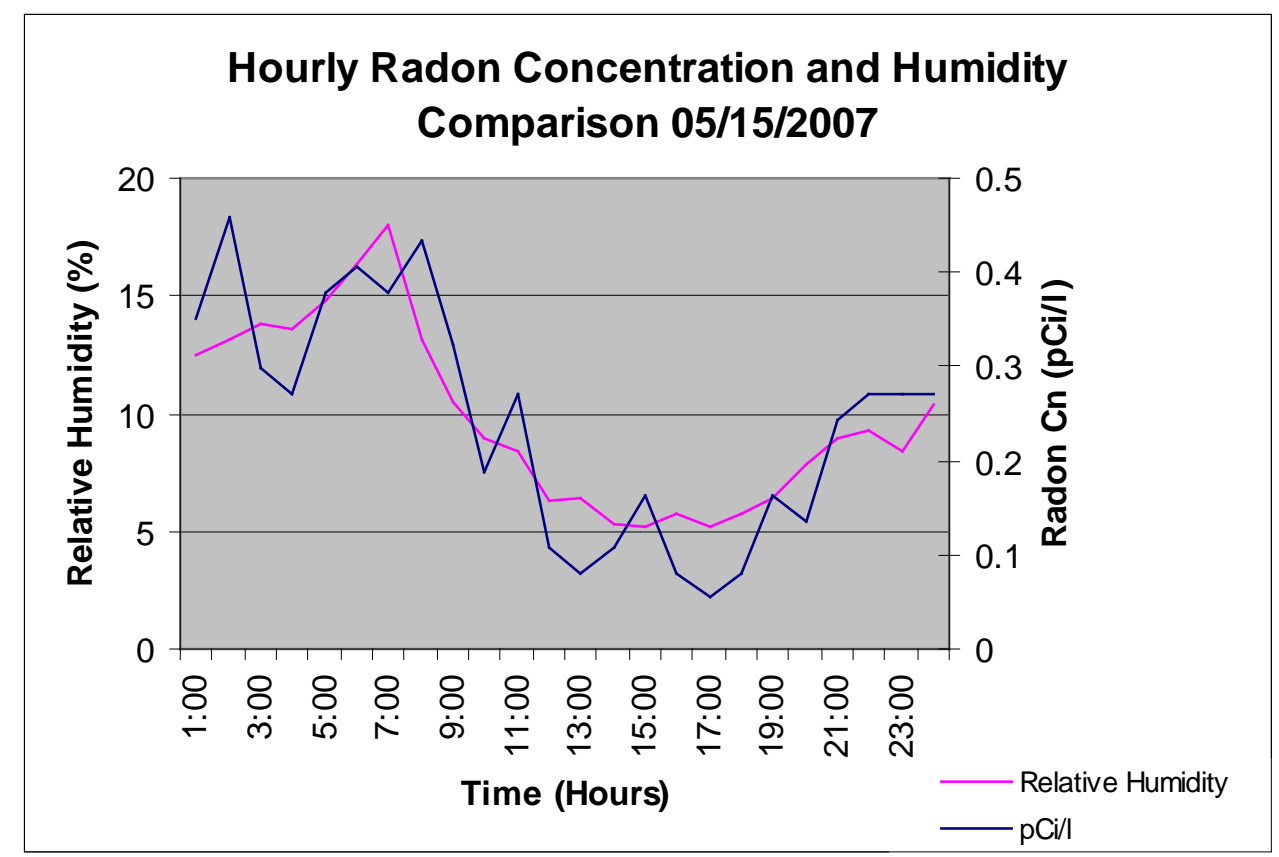

Figure A-2. Hourly AGS Rn concentration and humidity comparison 05/15/2007. 


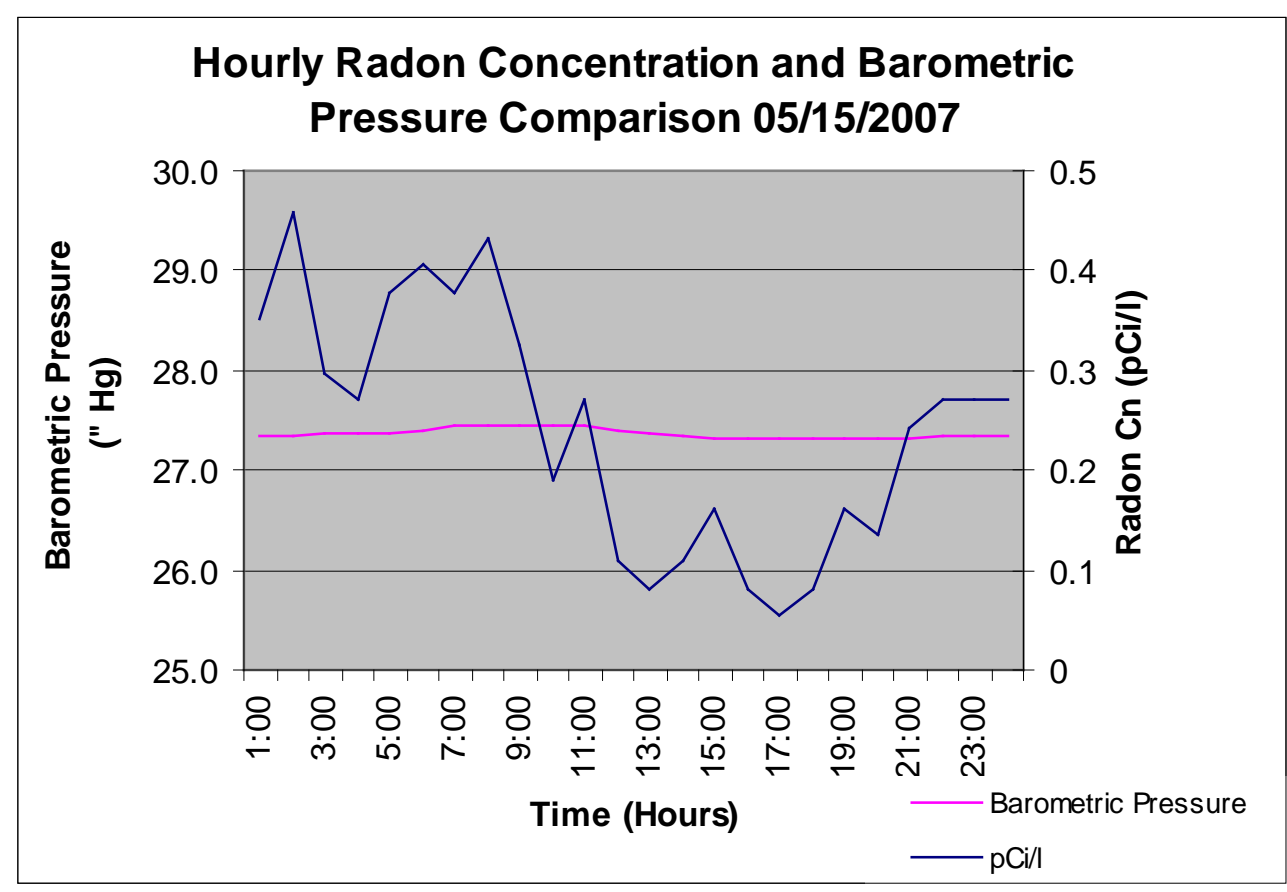

Figure A-3. Hourly AGS Rn concentration and barometric pressure comparison 05/15/2007.

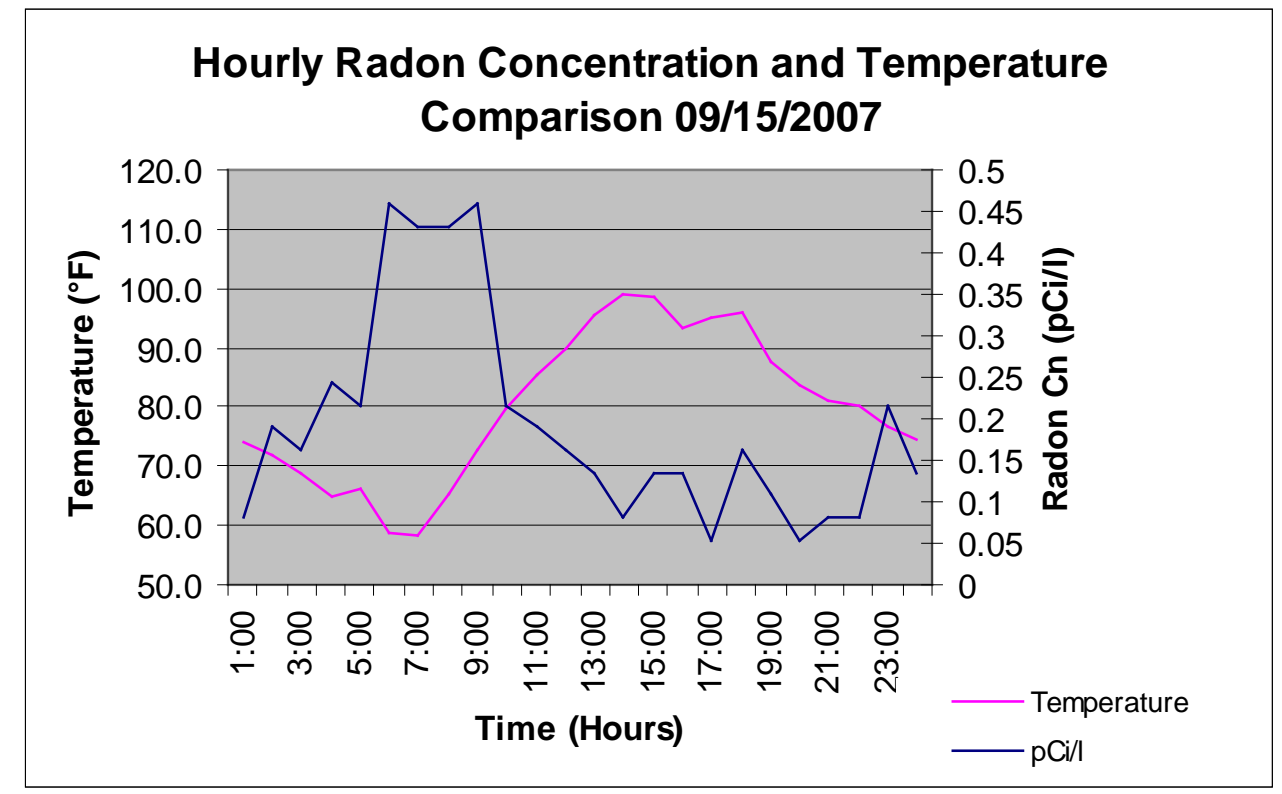

Figure A-4. Hourly AGS Rn concentration and temperature comparison 09/15/2007. 


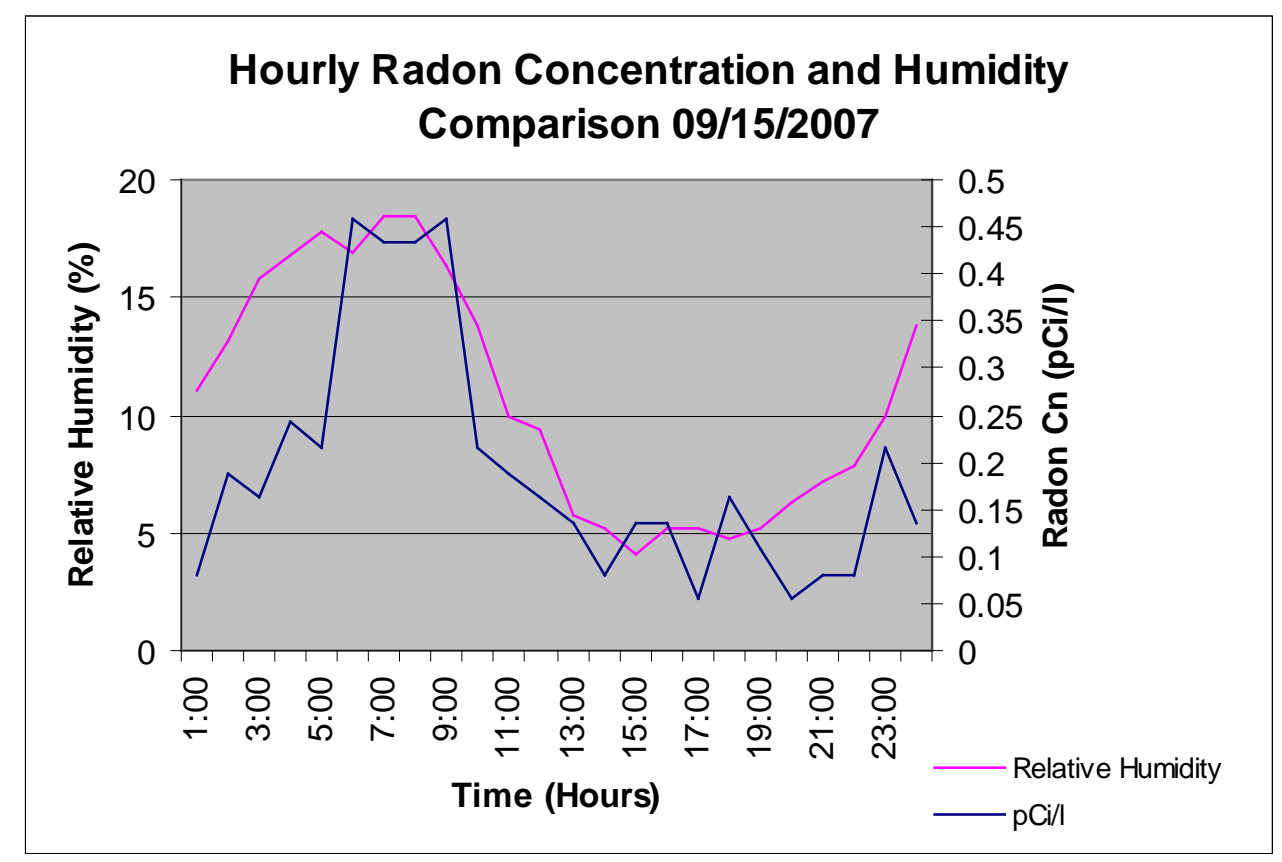

Figure A-5. Hourly AGS Rn concentration and humidity comparison 09/15/2007.

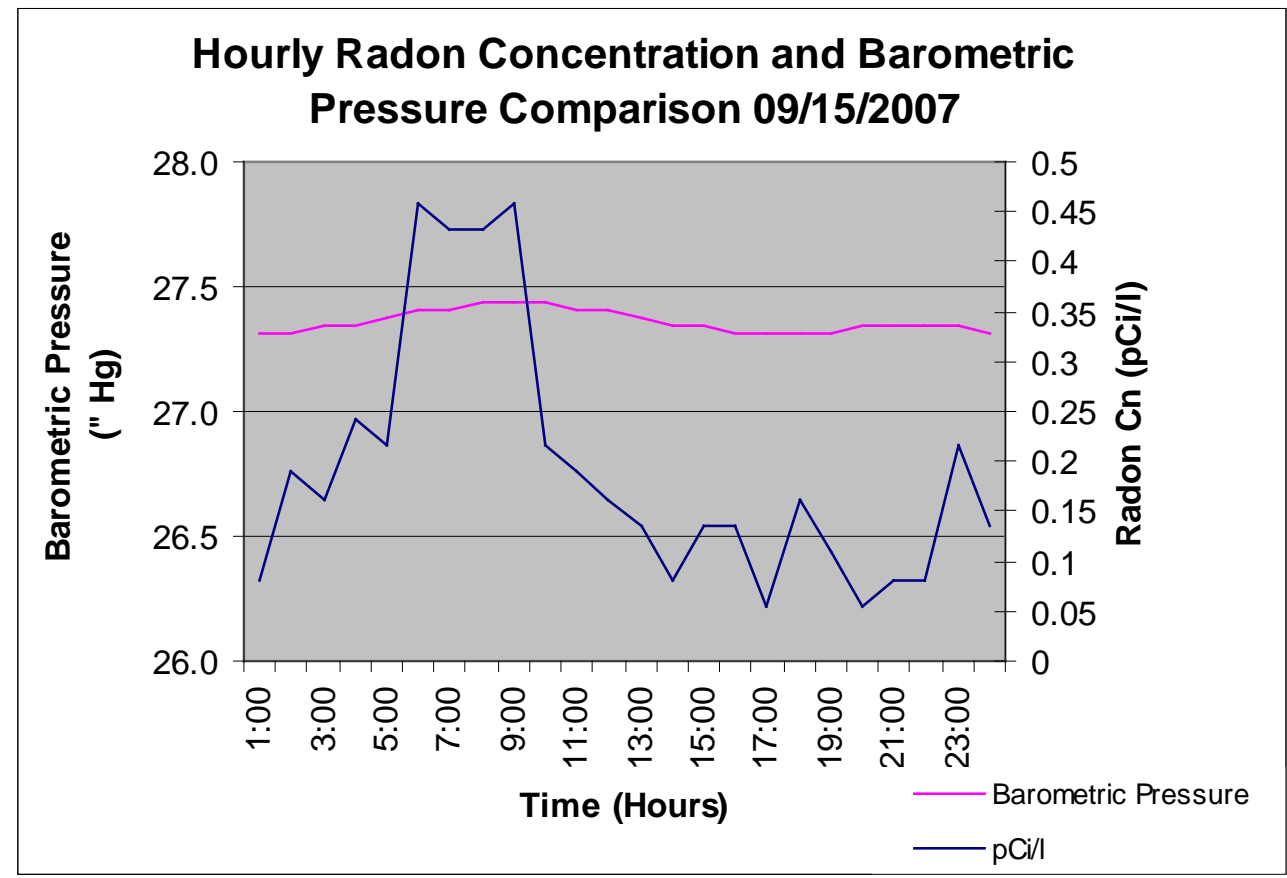

Figure A-6. Hourly AGS Rn concentration and barometric pressure comparison 09/15/2007. 


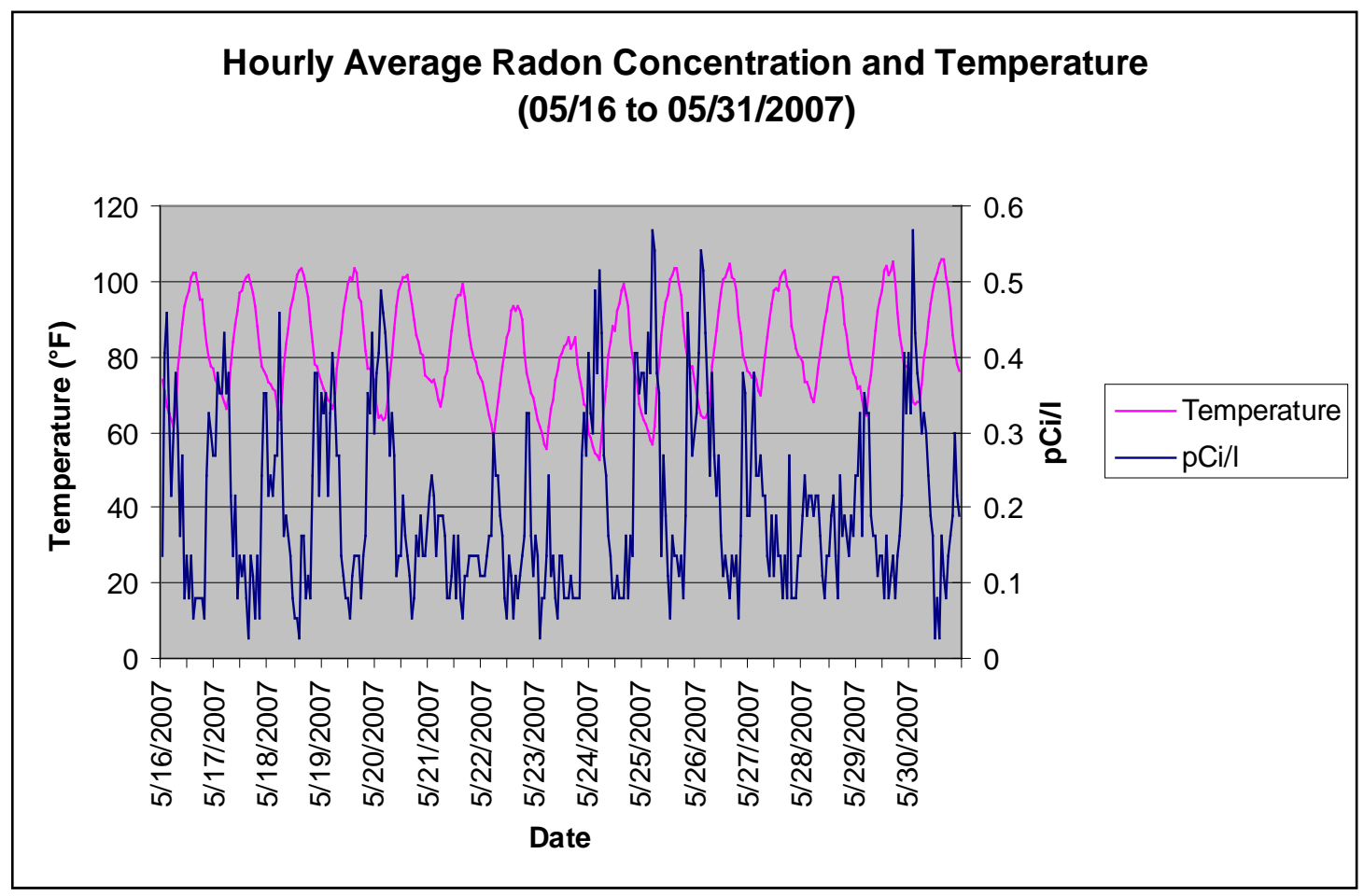

Figure A-7. Hourly average Rn concentration and temperature 05/16 to 05/31/2007.

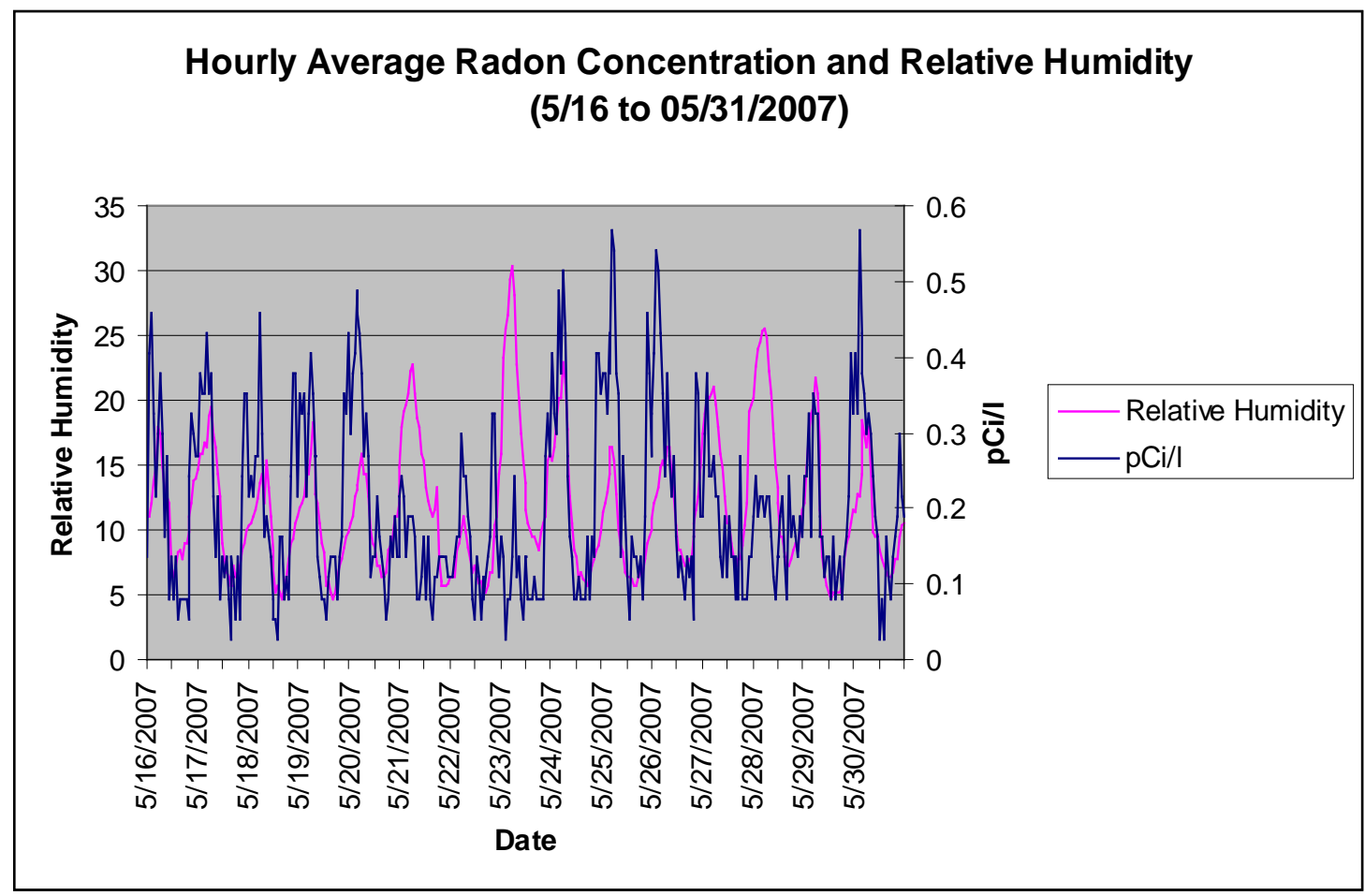

Figure A-8. Hourly average Rn concentration and relative humidity 05/16 to 05/31/2007. 


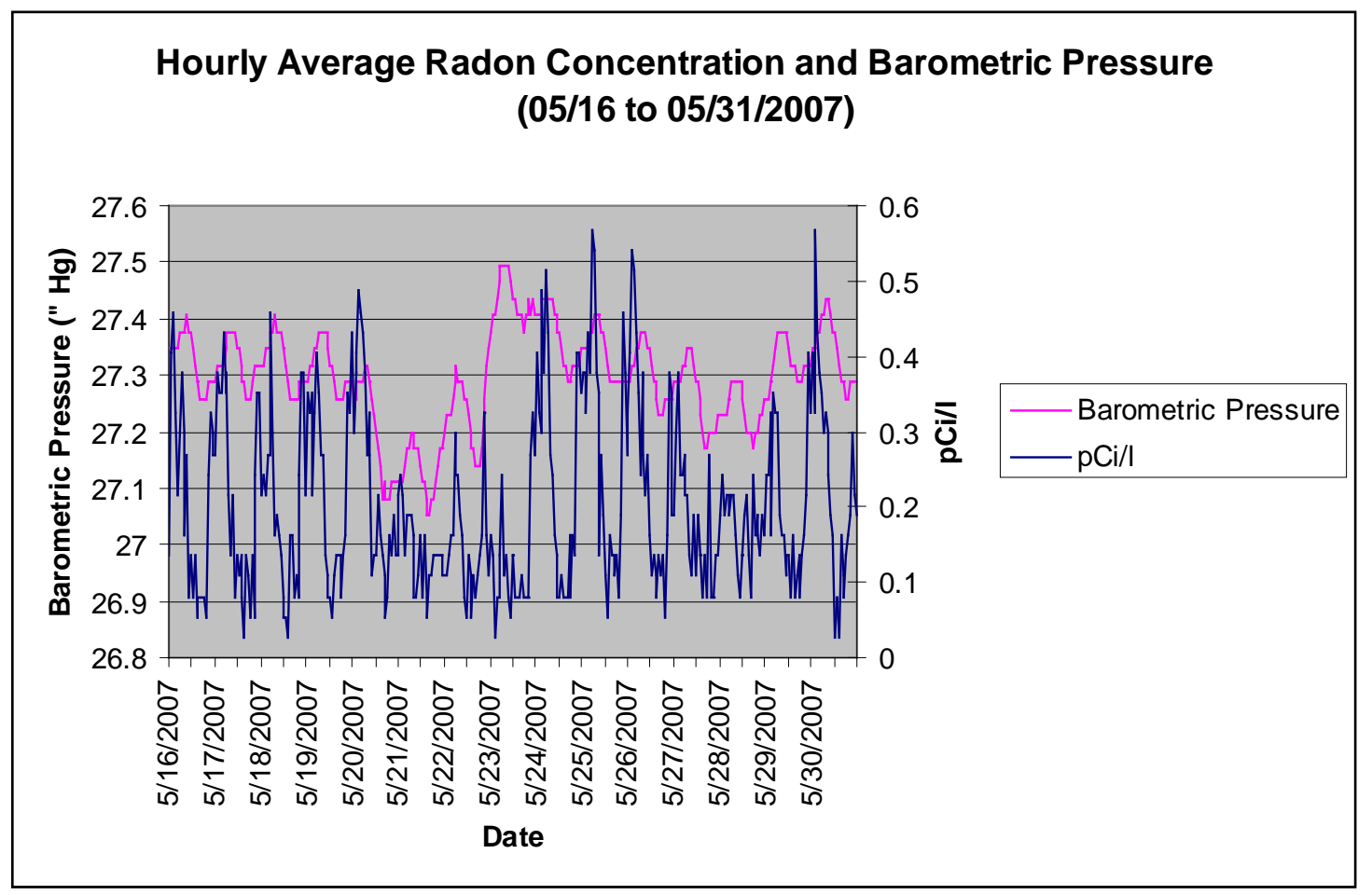

Figure A-9. Hourly average Rn concentration and barometric pressure 05/16 to 05/31/2007.

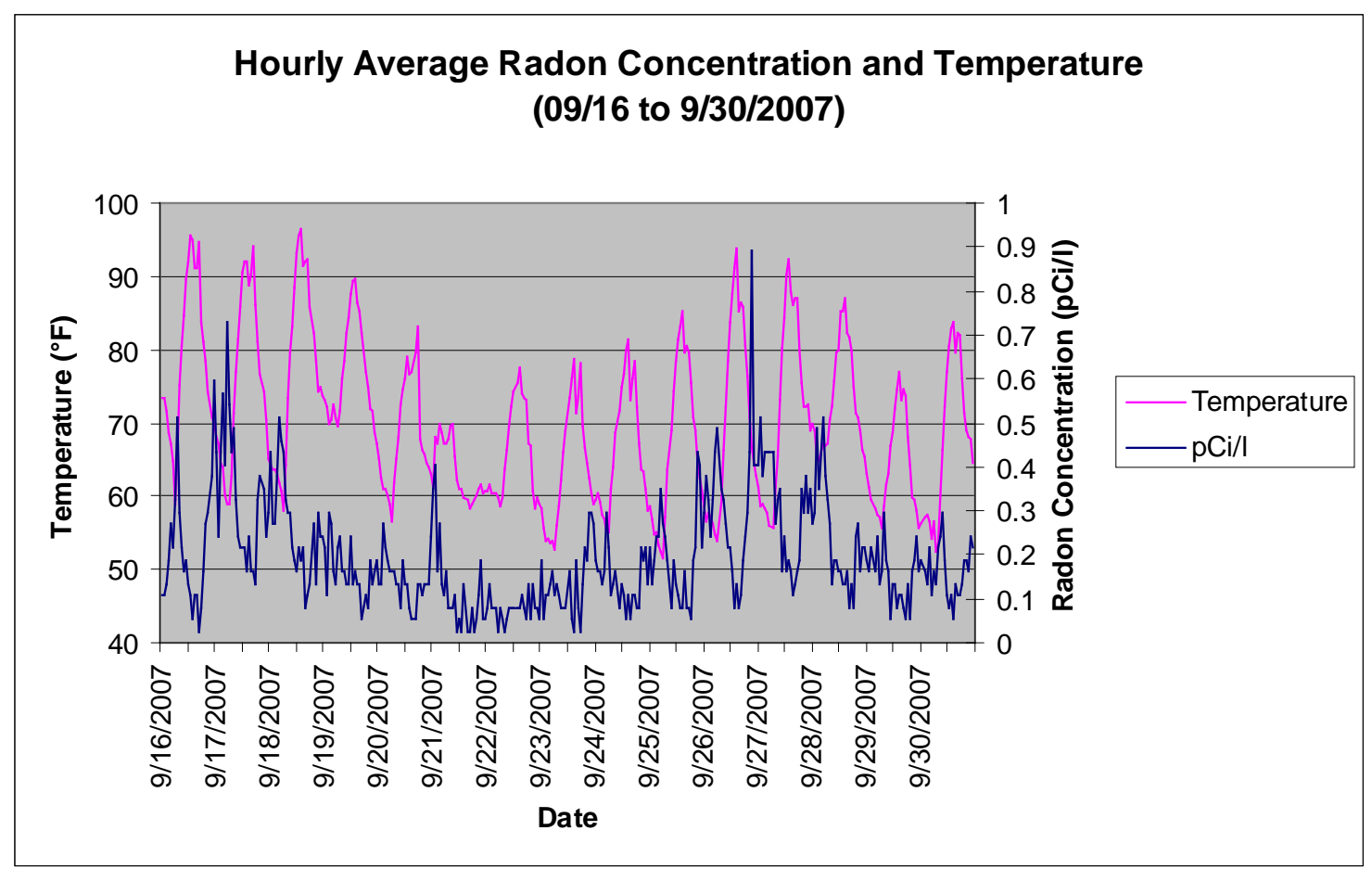

Figure A-10. Hourly average Rn concentration and temperature 09/16 to 09/30/2007. 


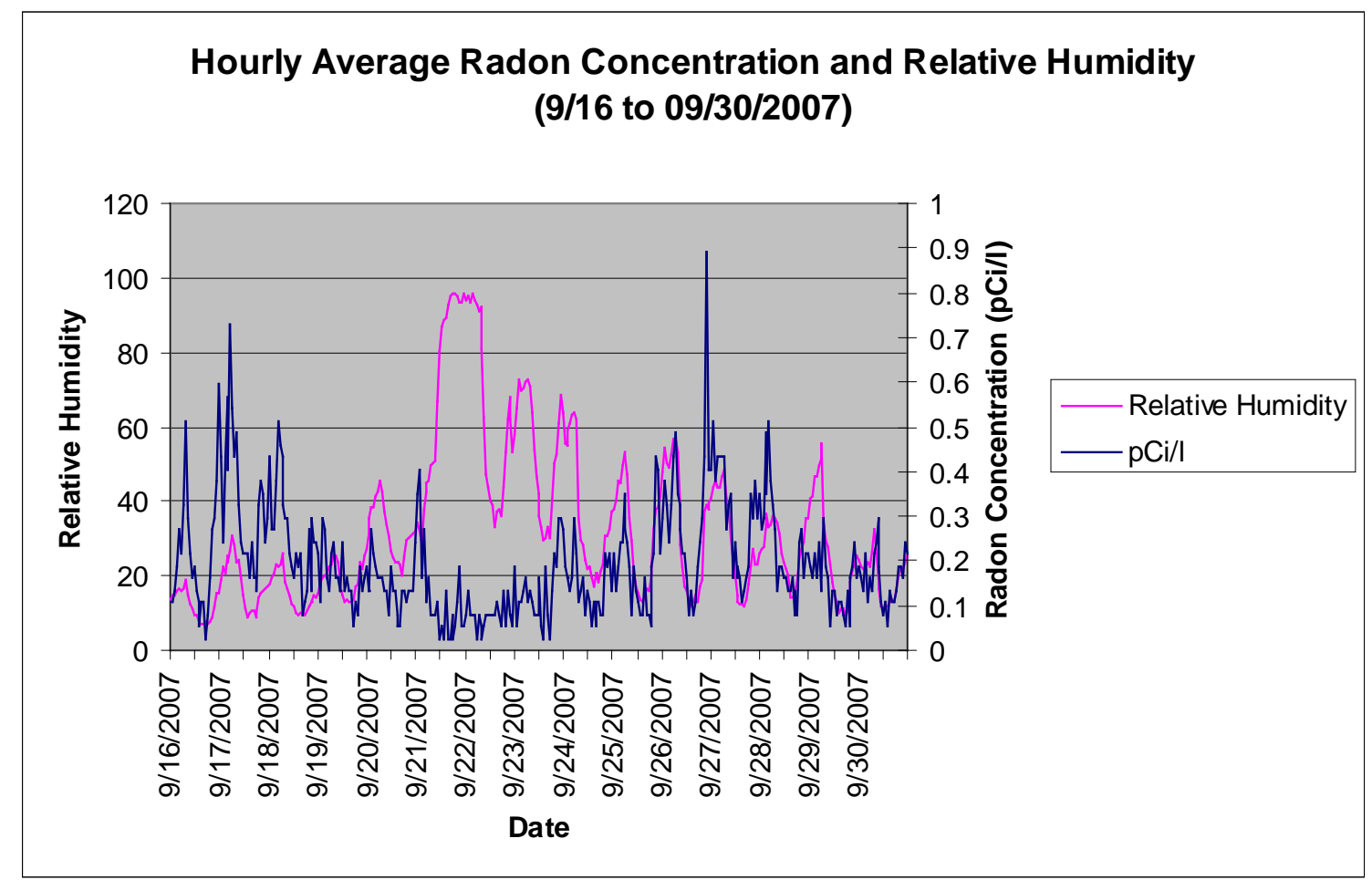

Figure A-11. Hourly average Rn concentration and relative humidity 09/16 to 09/30/2007.

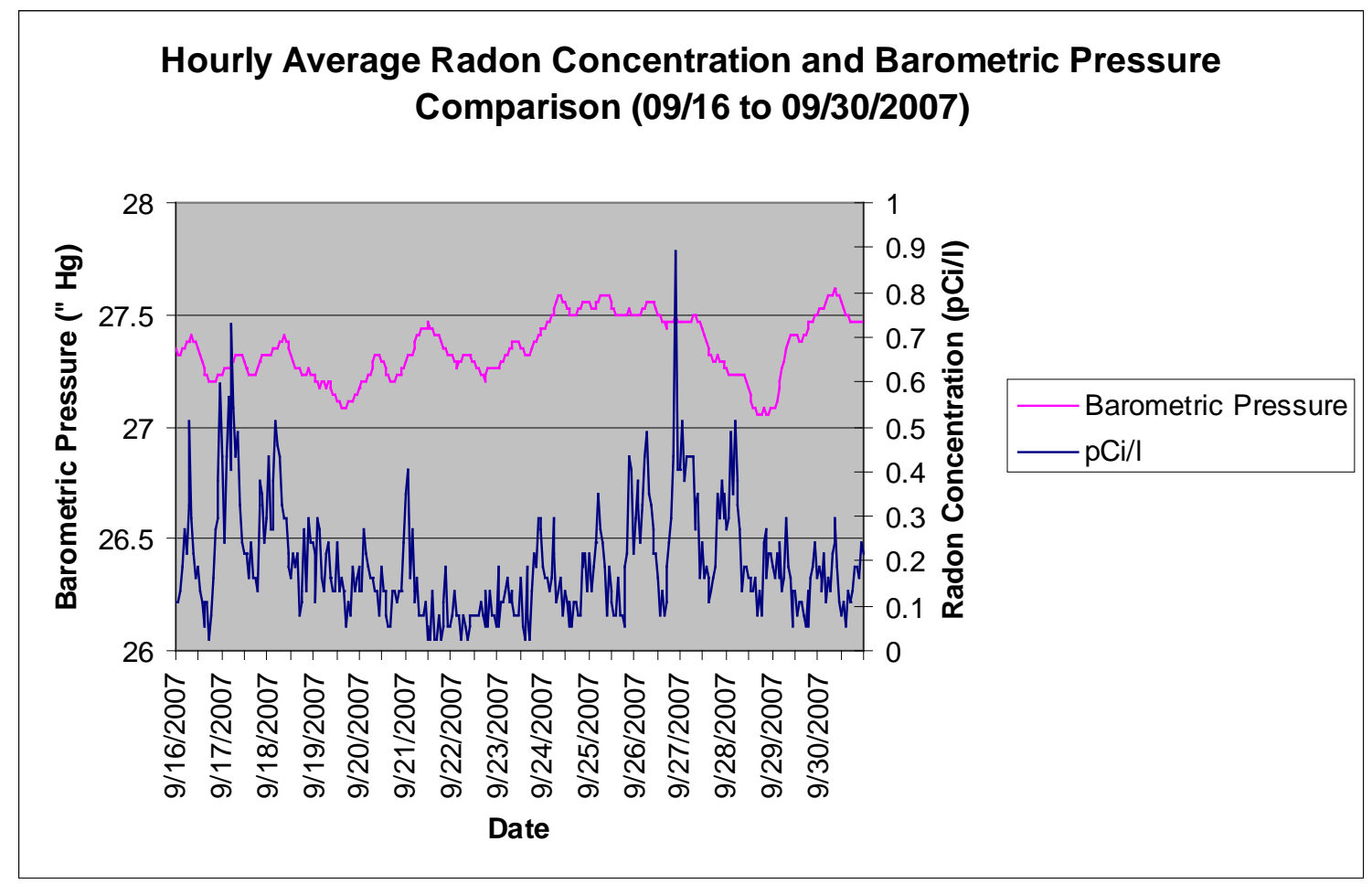

Figure A-12. Hourly average Rn concentration and barometric pressure comparison 09/16 to 09/30/2007. 


\section{APPENDIX B: COMPARISON OF ALPHAGUARD® AND CEMP ENVIRONMENTAL DATA}

\section{SUMMARY}

The purpose of these analyses was to compare the measured temperature (T), pressure (P), and relative humidity ( $\mathrm{rH}$ ) from the enclosed AlphaGuard monitoring system (AGS) and the adjacent Community Environmental Monitoring Program (CEMP) station. The data were paired values at each point in time where there exists a value for $\mathrm{T}, \mathrm{P}$, and $\mathrm{H}$ from each monitoring station. These analyses were performed on paired data from April 2007 to January 2008.

These analyses consisted of both quantitative and qualitative evaluation of the data. These analyses relate to the concept of statistical and practical significance. Statistical significance of the difference between data from the two instruments could have been achieved through methods such as the parametric t-test or a non-parametric signed rank test. However, the test statistic and corresponding p-value of these tests depended on not only the magnitude of the differences, but the number of points as well. Given enough data points, the t-test will always find a significant difference between the two instruments. Because these data sets contain several thousand data pairs, a t-test for each data set $(\mathrm{T}, \mathrm{P}, \mathrm{rH})$ revealed a statistically significant difference between the instruments in each case. However, though a statistically significant difference was found, the magnitude of the difference was sometimes determined to be practically insignificant. For example, there existed a statistically significant difference in pressure between the instruments, but the magnitude of the mean difference (approximately 0.25 millibars (mbars) was too small to be practically significant. Therefore, statistical significance was not used in this study to compare the instruments. Rather, a measure of practical significance, described below, was developed.

To evaluate the practical significance of the difference between instruments, a combination of graphical and simple descriptions of the data was conducted One can easily detect patterns and trends in the data when presented with an appropriate graph. For these analyses, the difference between the two instruments versus the mean value was plotted to determine if the AGS was less accurate at different absolute values; for example, it was found that the AGS reports temperatures as much as $41^{\circ} \mathrm{F}\left(5^{\circ} \mathrm{C}\right)$ higher than the CEMP station at higher temperatures. Also, the difference at different times of year was plotted to determine, for example, if the instruments behaved differently in summer than in winter.

To evaluate the practical significance of the differences, the 95 percent confidence interval of the mean difference was computed. Then, that interval was compared to a difference of 0.0 , which represents perfect agreement between the instruments. If the line of perfect agreement, where the difference equals 0.0, falls within the 95 percent confidence interval, it can be concluded there is no practical difference in data from the two instruments. However, even if the line of perfect agreement falls outside of the 95 percent confidence interval, the relative magnitude of the difference may be small enough to be practically insignificant. 


\section{DISCUSSION}

\section{Temperature}

For the entire data set (Figure 1), the mean difference was $2.61^{\circ} \mathrm{F}\left(1.45^{\circ} \mathrm{C}\right)$ with a 95 percent confidence interval for the mean of $+/-0.09^{\circ} \mathrm{F}(+/-0.05$ degrees $\mathrm{C})$. Also, the differences were greater at higher temperatures. At temperatures above $86^{\circ} \mathrm{F}\left(30^{\circ} \mathrm{C}\right)$ the difference increased to as much as 5 or 6 degrees.

Figure 2 and Figure 3 show the monthly comparison between the two stations. In each month the temperature in the AGS was generally higher than that in the CEMP station. Mean differences ranged from $+32.36{ }^{\circ} \mathrm{F}\left(+0.2{ }^{\circ} \mathrm{C}\right)$ in January to $+0.36{ }^{\circ} \mathrm{F}\left(+2.2^{\circ} \mathrm{C}\right)$ in July. Practically, a difference of less than $3.96^{\circ} \mathrm{F}\left(2^{\circ} \mathrm{C}\right)$ may not be significant. However, the largest differences are usually found at the higher temperatures.

\section{Relative Humidity}

For the entire data set (Figure 4), the mean difference was -1.55 percent for $\mathrm{rH}$ with a 95 percent confidence interval for the mean of $+/-0.10$ percent. Also, the range of differences was greater at higher relative humidity, implying that the accuracy of the AGS was lower under these conditions.

Differences in humidity can be seen over time. As show in Figure 5 and Figure 6 below, the variation in difference was higher from October through January-the time of year when humidity was slightly higher. The greatest mean difference of $-3.8+/-0.5$ percent was found in December, while the lowest ( $-0.45+/-0.1$ percent) was found in June. Differences in relative humidity were as high as 20 percent. Such differences are statistically and practically significant.

\section{Pressure}

For the entire data set (Figure 7), the mean difference was 0.25 mbar with a 95 percent confidence interval for the mean of $+/-0.02$ mbar. This difference was practically insignificant given the assumed accuracy of the instruments of $+/-0.5$ mbar. The error in pressure changed over time (Figure 8 and Figure 9). In April, May, and October through January the AGS recorded higher pressure, while from June through September, the AGS recorded lower pressure than the CEMP station. The AGS was least accurate in January with a mean difference of $+1.44+/-0.04$ mbar and was most accurate in May with a mean difference of $+0.19+/-0.03$ mbar. These differences were assumed to be practically insignificant.

\section{CONCLUSIONS}

\section{Temperature}

- Temperature recorded by the AGS was $2.61+/-0.09^{\circ} \mathrm{F}\left(1.45+/-0.05^{\circ} \mathrm{C}\right)$ higher overall.

- The AGS was least accurate in July (mean difference of $+3.96+/-0.27^{\circ} \mathrm{F}$ $\left(+2.2+/-0.15^{\circ} \mathrm{C}\right)$ and most accurate in January (mean difference of $+0.36+/-0.2^{\circ} \mathrm{F}\left(+0.2+/-0.11^{\circ} \mathrm{C}\right)$.

- The AGS was less accurate at higher temperatures.

- Practically, the difference between the two instruments may not have been significant. 


\section{Relative Humidity}

- Overall, relative humidity was 1.55 +/- 0.1 percent lower in the AGS than in the CEMP station.

- The AGS was least accurate in December (mean difference of $-3.8+/-0.5$ percent) and most accurate in June (mean difference of $-0.45+/-0.1$ percent).

- The AGS was less accurate at higher relative humidity.

- Practically, the difference between the two instruments was significant.

\section{Pressure}

- Overall, the pressure recorded in the AGS was 0.25 +/- 0.02 mbar higher than that recorded by the CEMP station.

- The AGS was least accurate in January with a mean difference of +1.44 +/- 0.04 mbar and most accurate in May with a mean difference of $+0.19+/-0.03$ mbar.

- $\quad$ These differences were assumed to be practically insignificant.

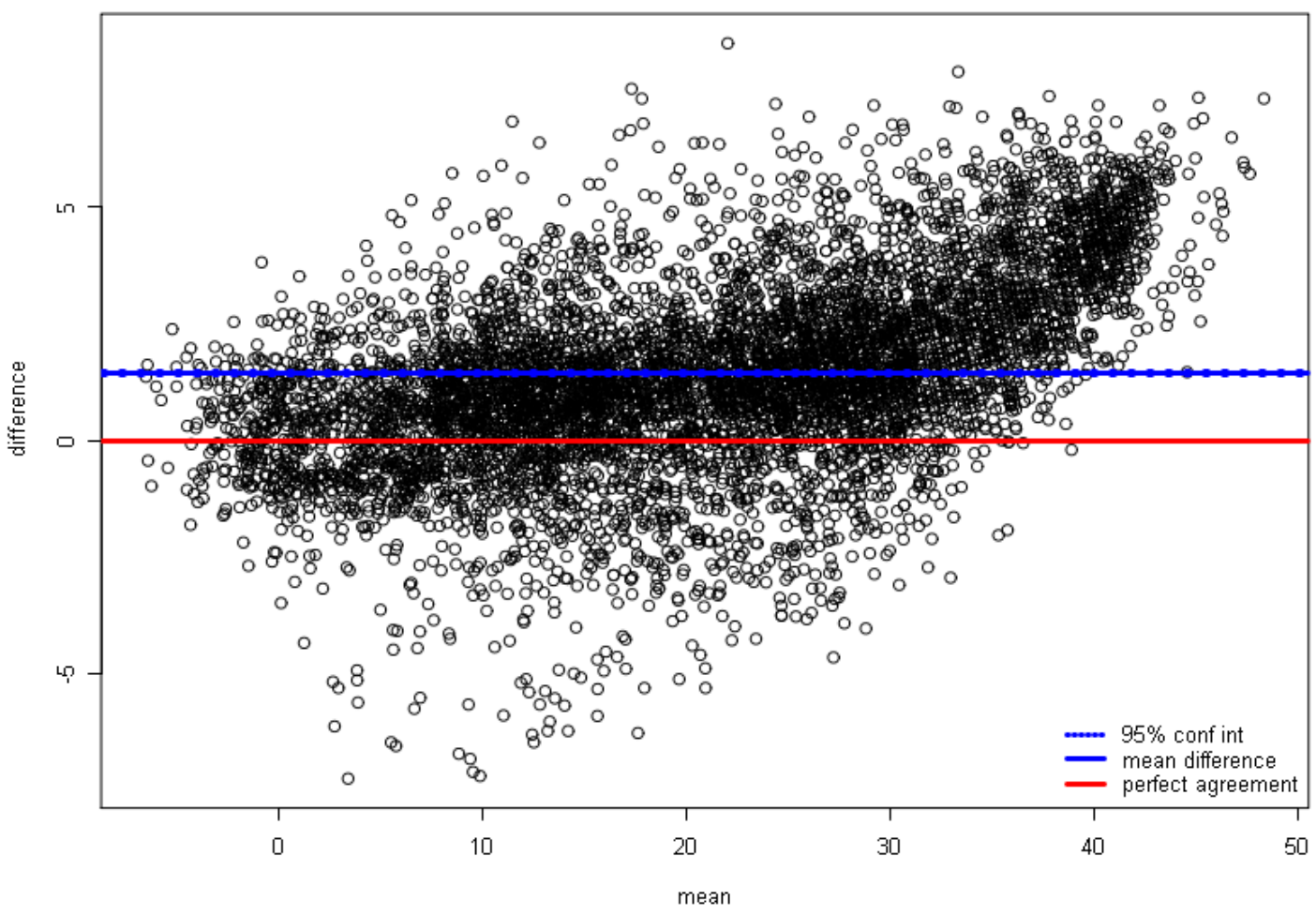

Figure B-1. Temperature difference. 

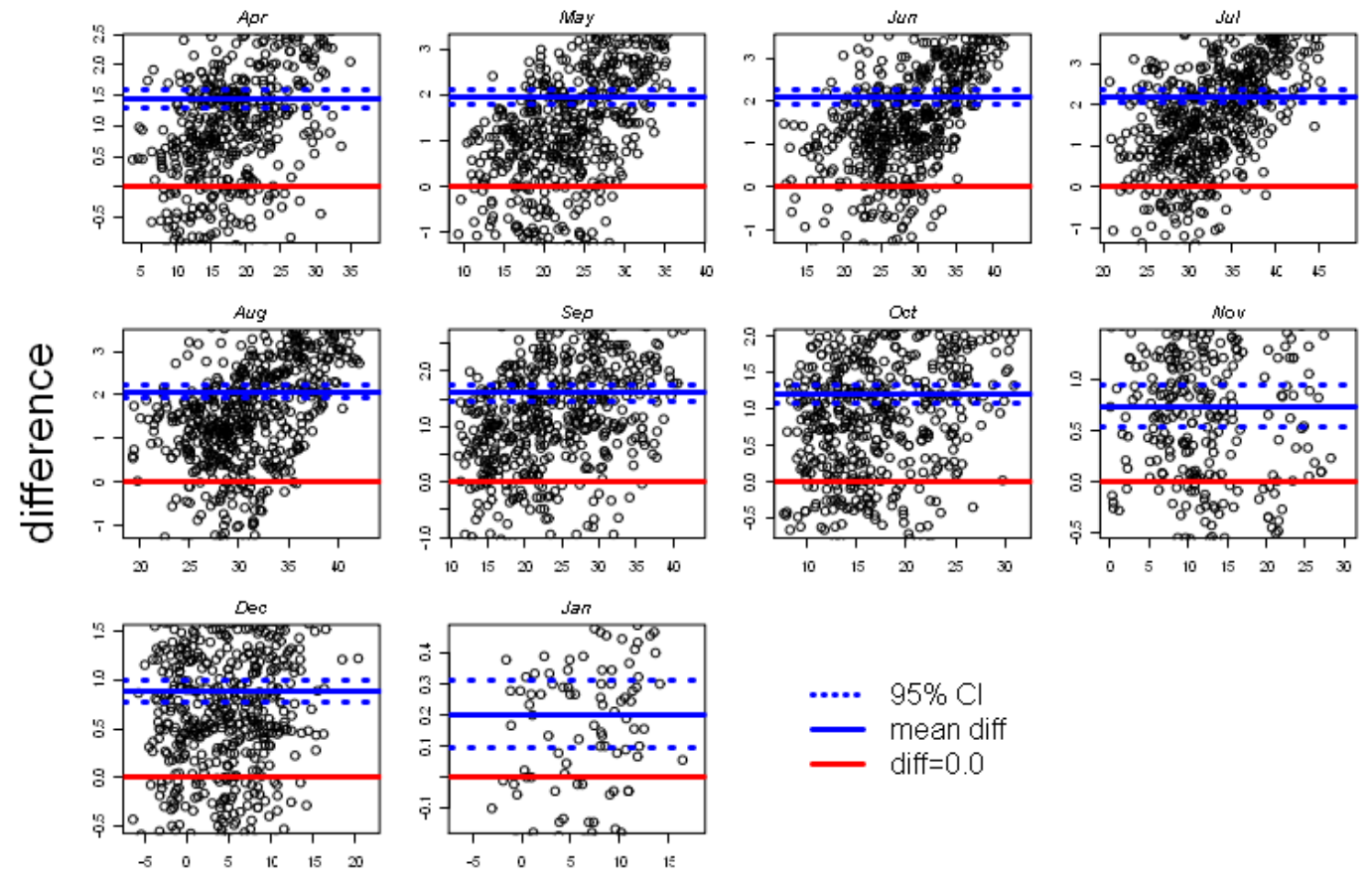

mean

Figure B-2. Monthly temperature difference.

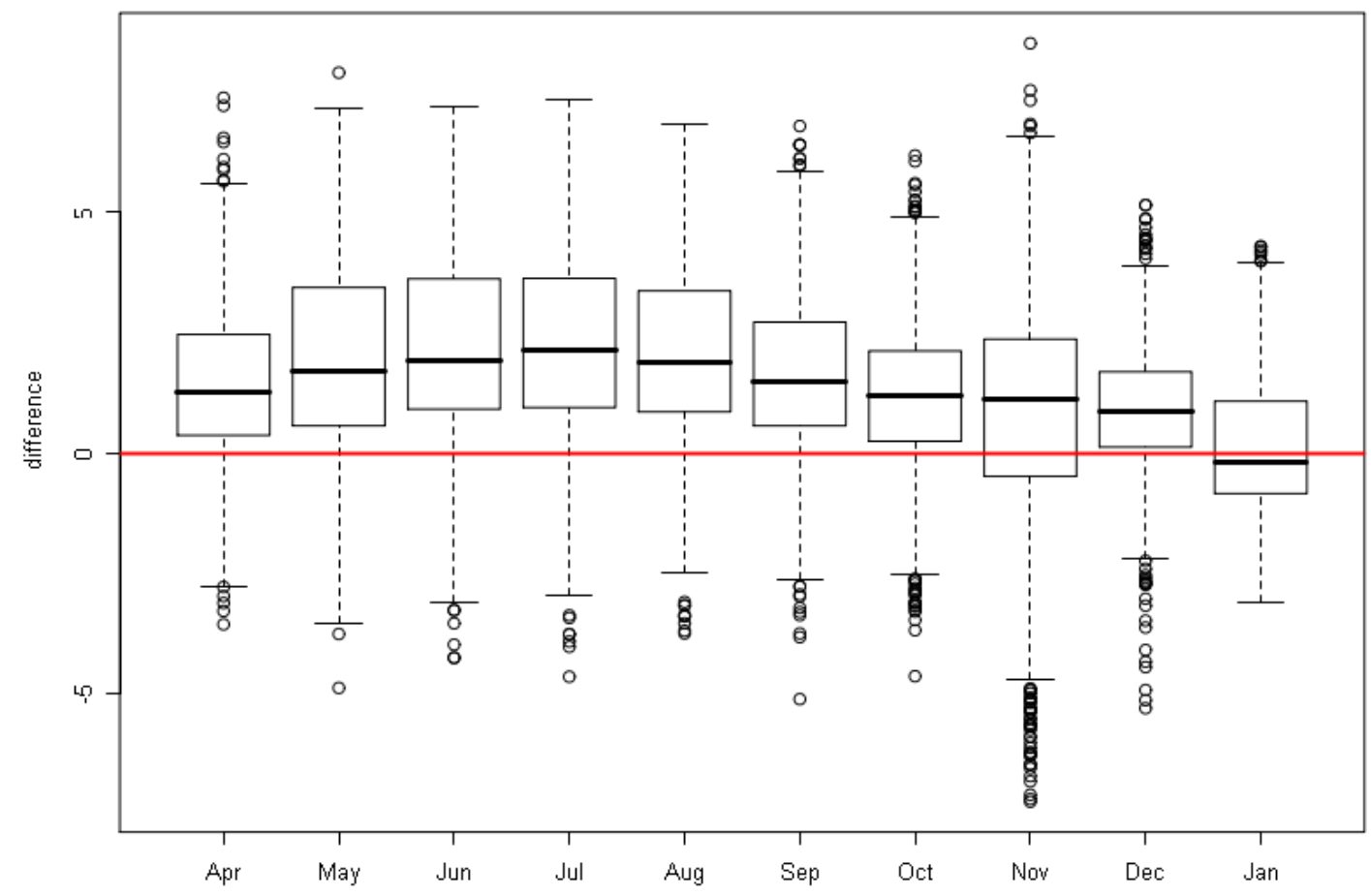

Figure B-3. Boxplots of monthly temperature difference. 


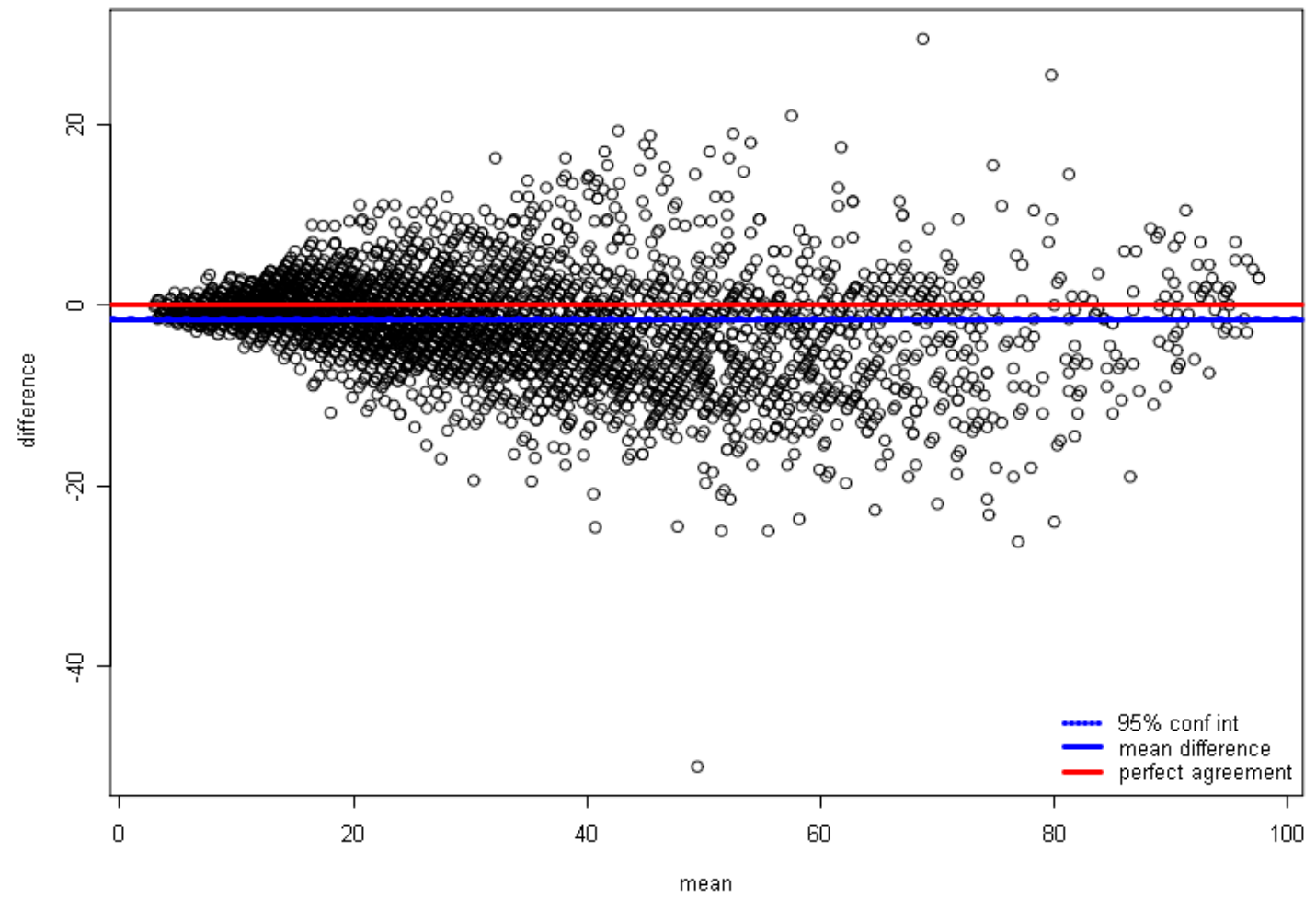

Figure B-4. Relative humidity difference.
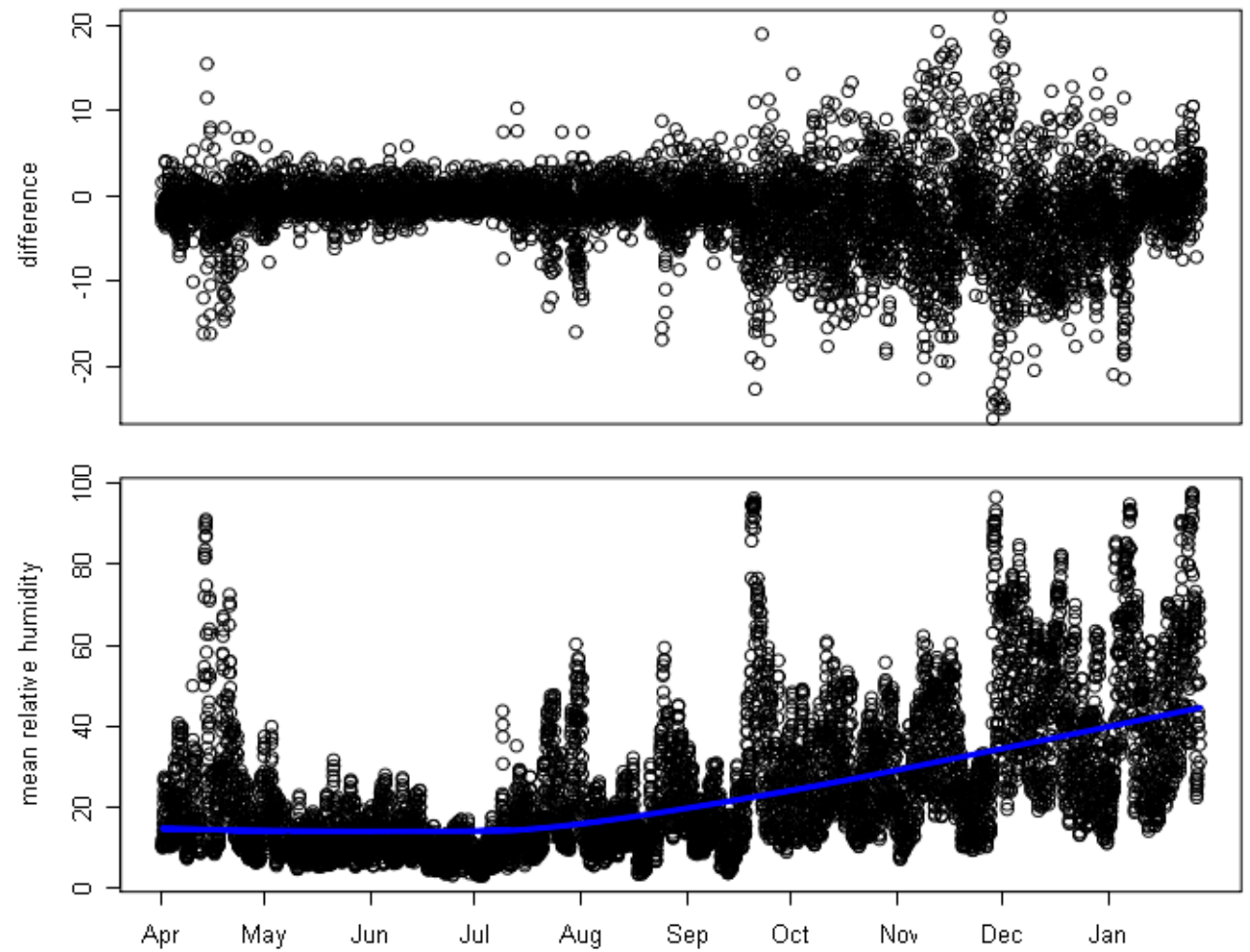

Figure B-5. Relative humidity difference over time. 

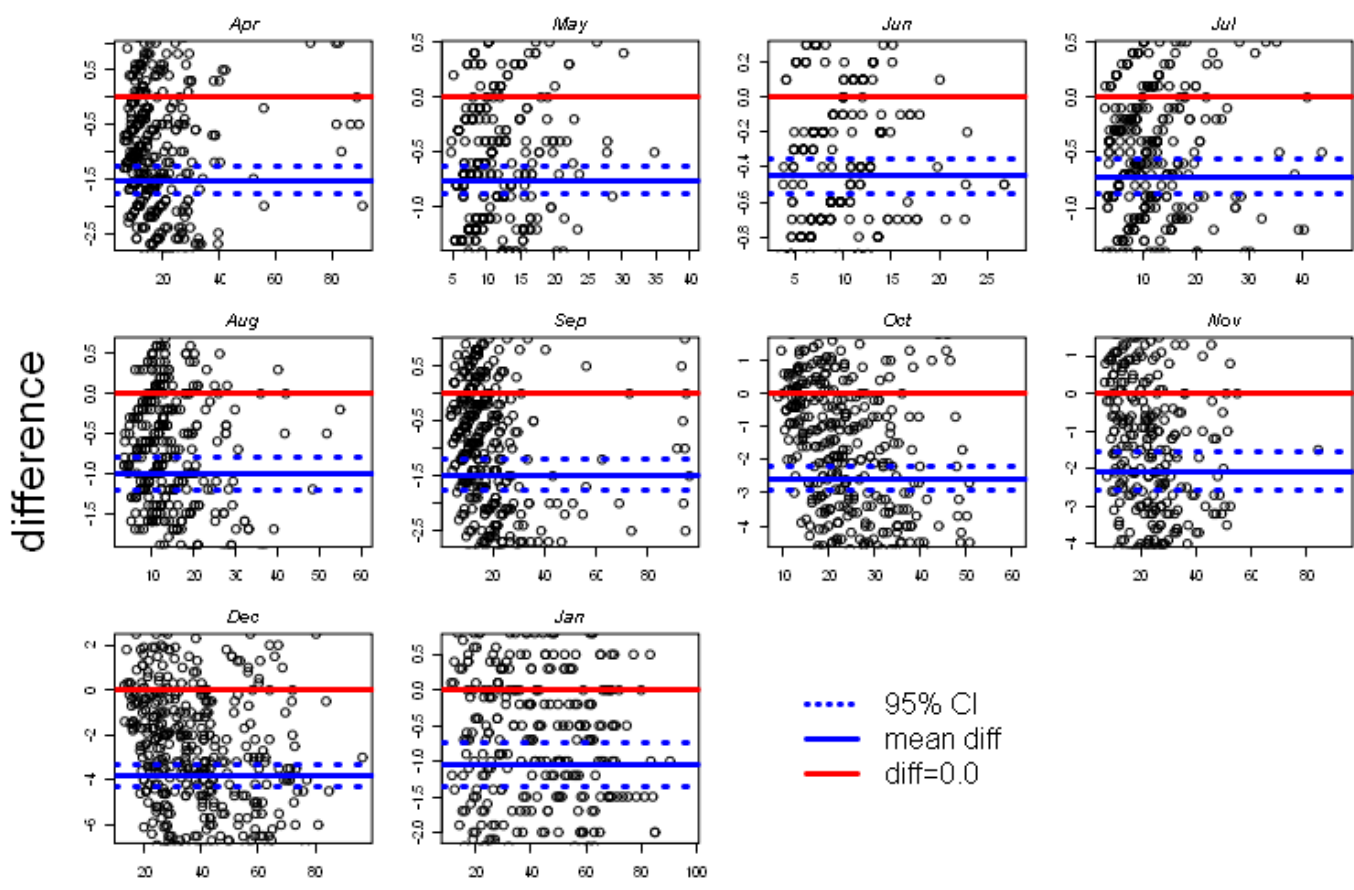

mean

Figure B-6. Monthly relative humidity difference.

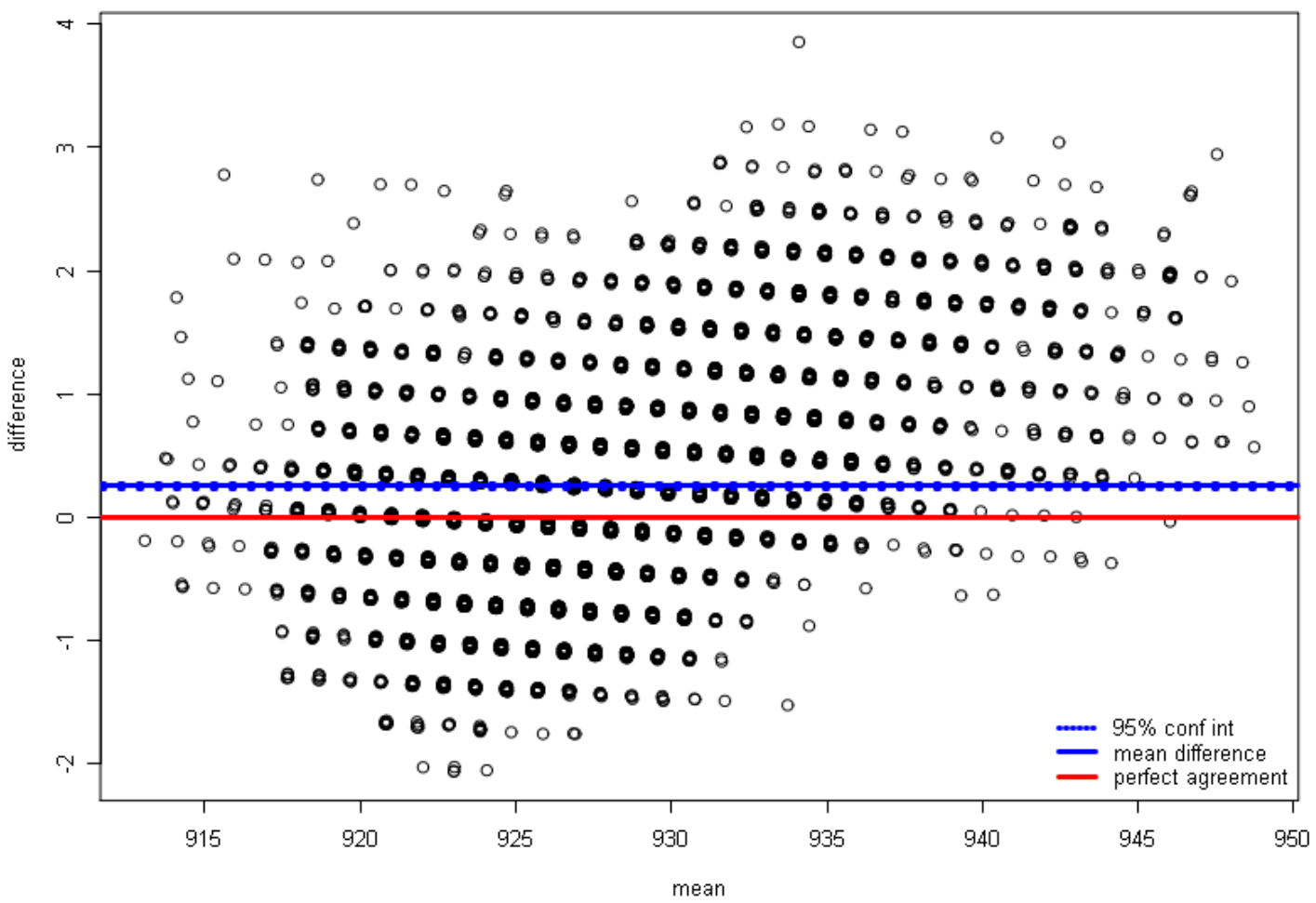

Figure B-7. Pressure difference. 

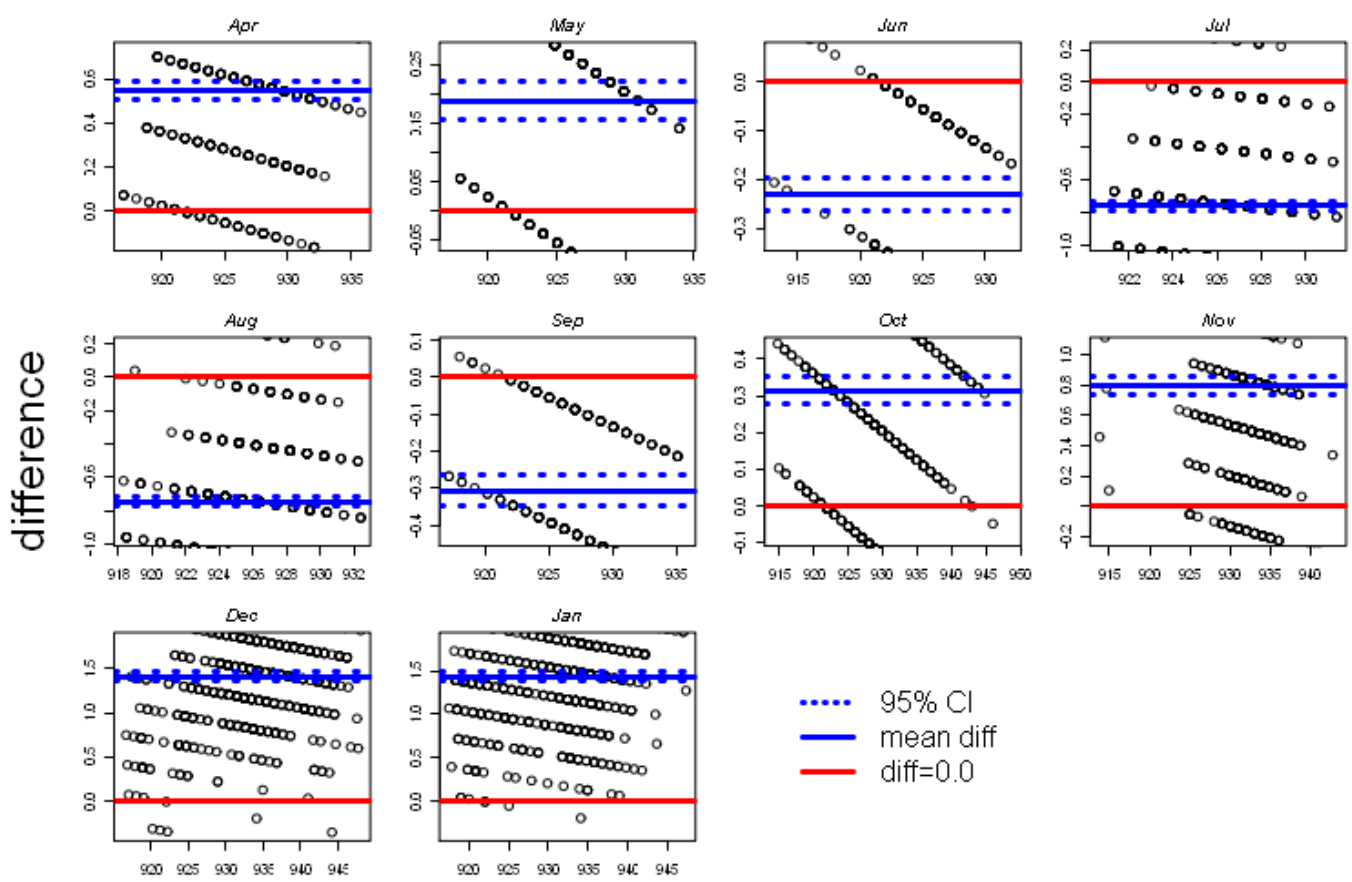

mean

Figure B-8. Monthly pressure difference.

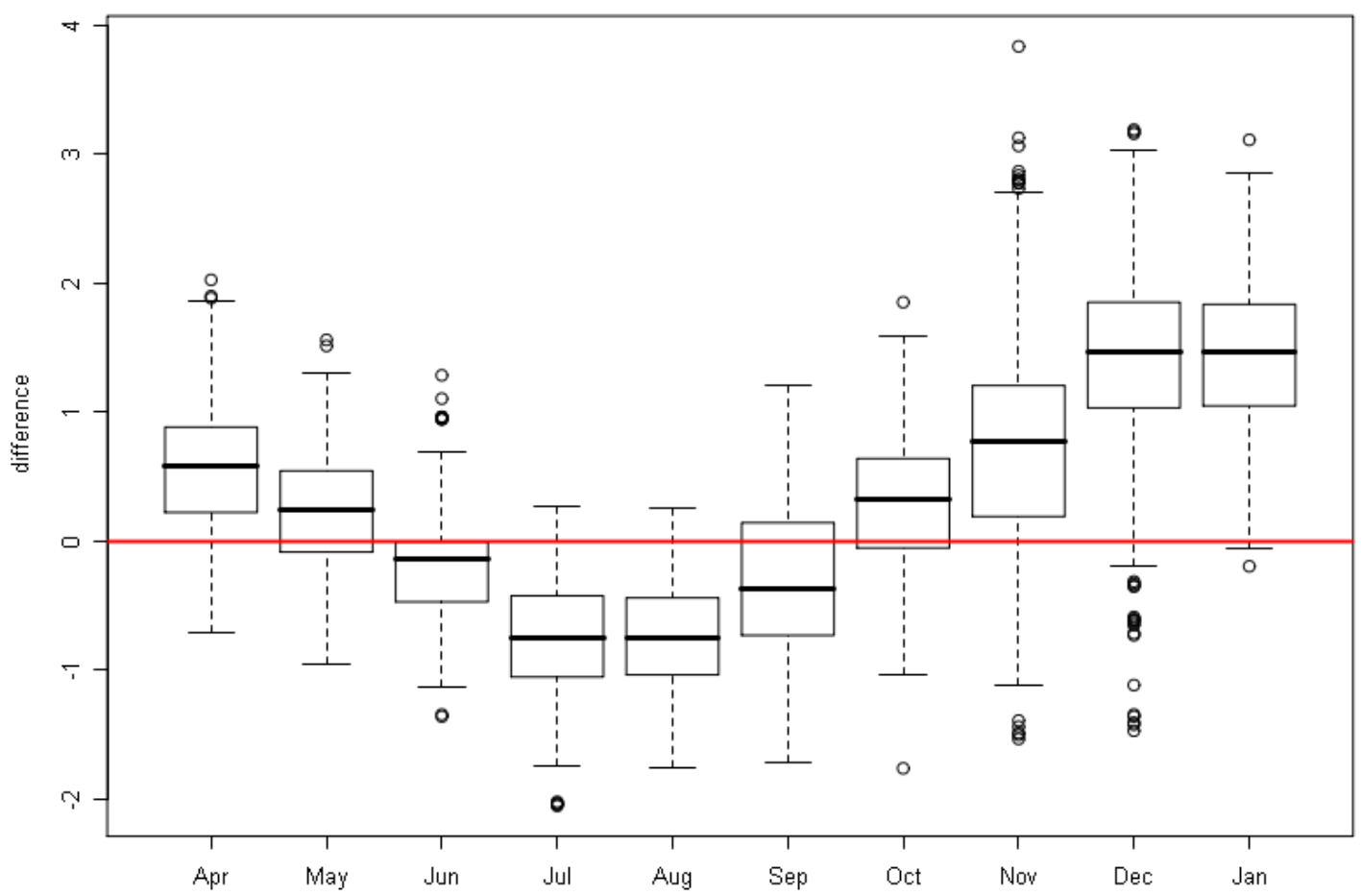

Figure B-9. Boxplots of monthly pressure differences. 